Author(s):

\section{Submitted to:}

Robert A. Krakowski

\section{DISCLAIMER}

This report was prepared as an account of work sponsored by an agency of the United States Government. Neither the United States Government nor any agency thereof, nor any of their employees, makes any warranty, express or implied, or assumes any legal liability or responsibility for the accuracy, completeness, or usefulness of any information, apparatus, product, or process disclosed, or represents that its use would not infringe privately owned rights. Reference herein to any specific commercial product, process, or service by trade name, trademark, manufacturer, or otherwise does not necessarily constitute or imply its endorsement, recommendation, or favoring by the United States Government or any agency thereof. The views and opinions of authors expressed herein do not necessarily state or reflect those of the United States Government or any agency thereof.

\section{APT Program Office Review}

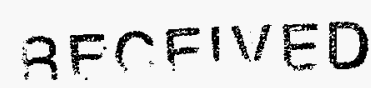

MAR 101995

OSTI

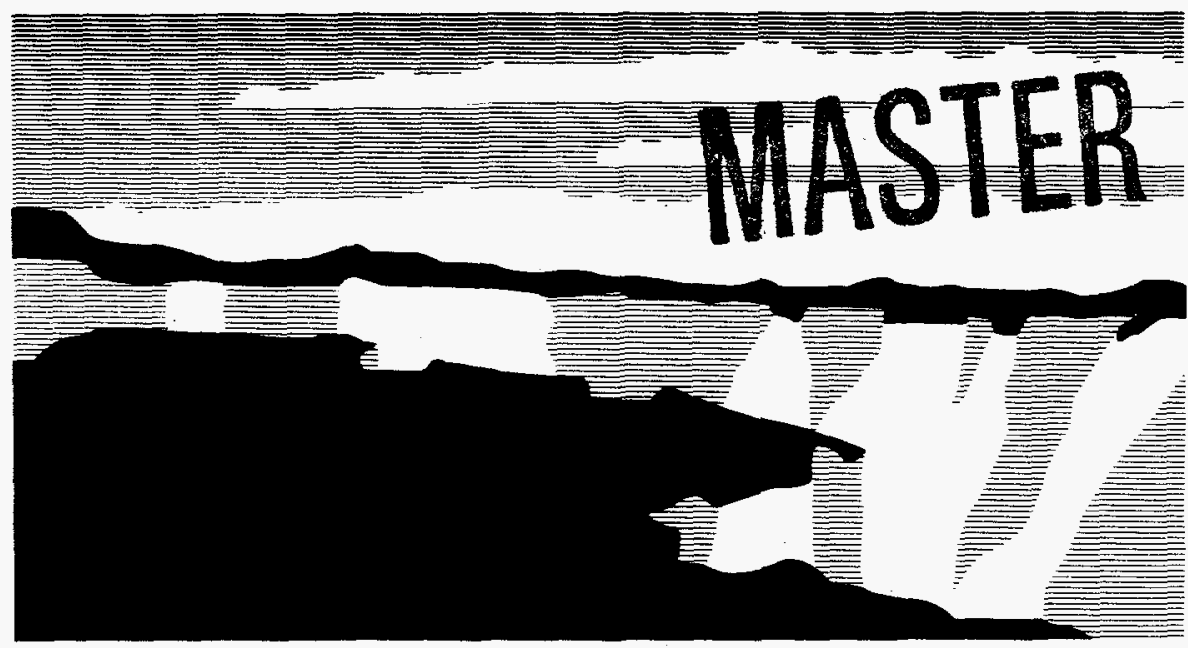

Los Alamos National Laboratory, an affirmative action/equal opportunity emplóyer, is operated by the University of California for the U.S. Department of Energy under contract W-7405-ENG-36. By acceptance of this article, the publisher recognizes that the U.S. Government retains a nonexclusive, royalty-free license to publish or reproduce the published form of this contribution, or to allow others to do so, for U.S. Government purposes. The Los Alamos National Laboratory requests that the publisher identify this article as work performed under the auspices of the U.S. Department of Energy. 


\section{DISCLAIMER}

Portions of this document may be illegible in electronic image products. Images are produced from the best available original document. 


\title{
APT COST SCALING: PRELIMINARY INDICATIONS FROM A PARAMETRIC COSTING MODEL (PCM)
}

\author{
R. A. Krakowski \\ Systems Integration and Integration Group \\ Group TSA-3 \\ February 3, 1995
}

\begin{abstract}
A Parametric Costing Model has been created and evaluate as a first step in quantitatively understanding important design options for the Accelerator Production of Tritium (APT) concept. This model couples key economic and technical elements of APT in a two-parameter search of beam energy and beam power that minimizes costs within a range of operating constraints. The costing and engineering depth of the Parametric Costing Model is minimal at the present "entry level", and is intended only to demonstrate a potential for a more-detailed, cost-based integrating design tool. After describing the present basis of the Parametric Costing Model and giving an example of a single parametric scaling run derived therefrom, the impacts of choices related to resistive versus superconducting accelerator structures and cost of electricity versus plant availability ("load curve") are reported. Areas of further development and application are suggested.
\end{abstract}

Table of Contents

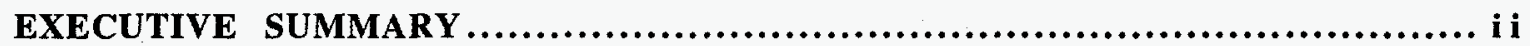

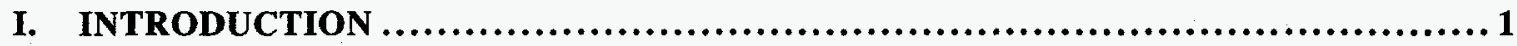

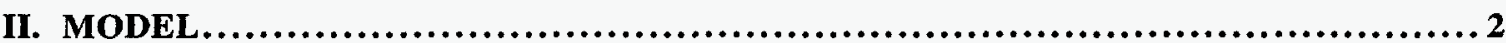

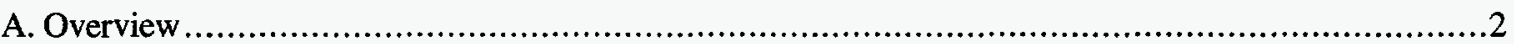

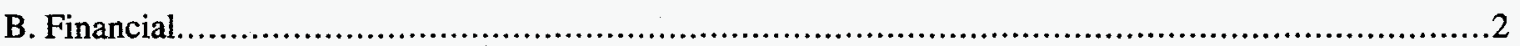

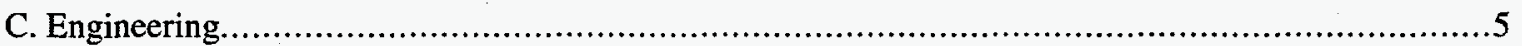

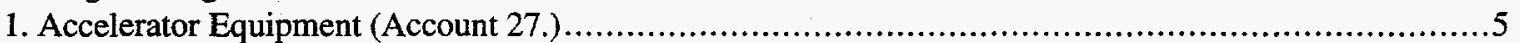

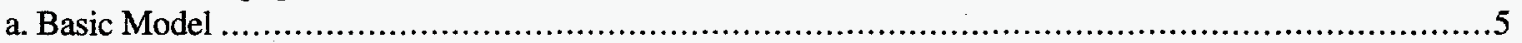

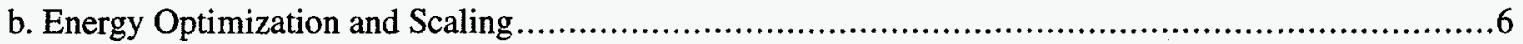

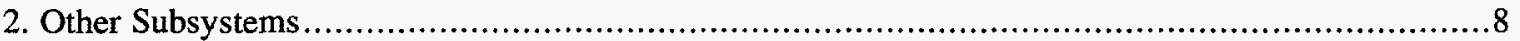

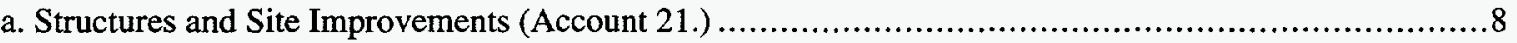

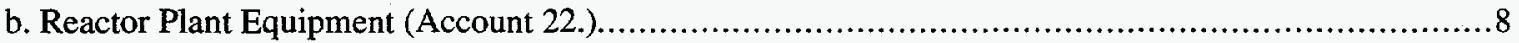

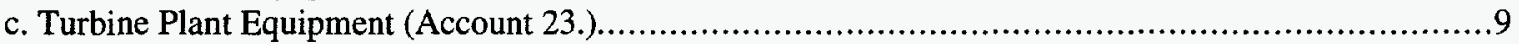

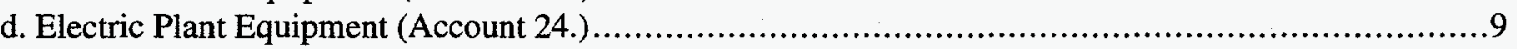

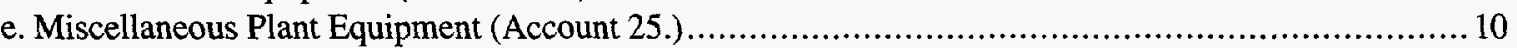

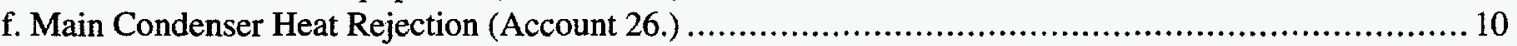

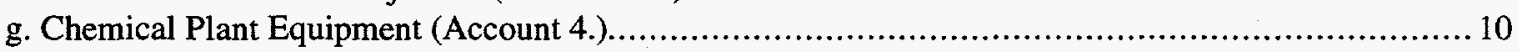

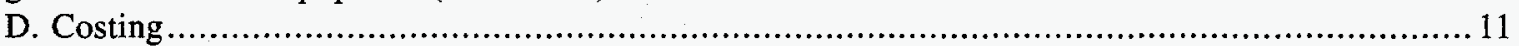

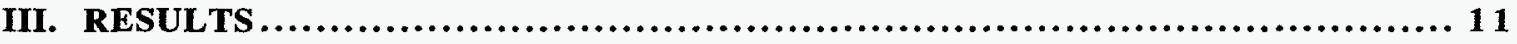

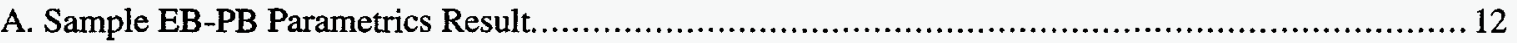

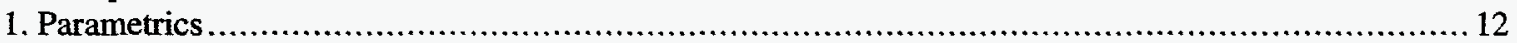

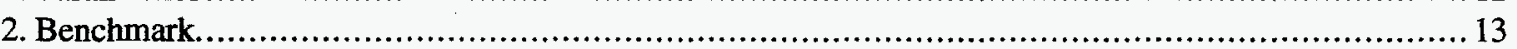

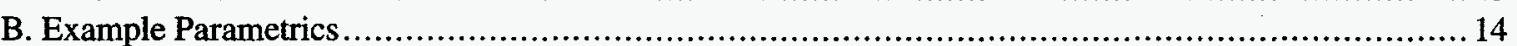

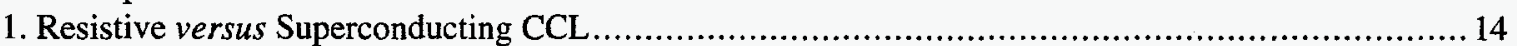

2. Load Curve: Cost of Electricity versus Plant Availability ................................................... 14

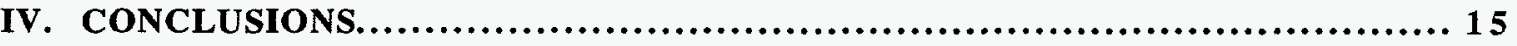

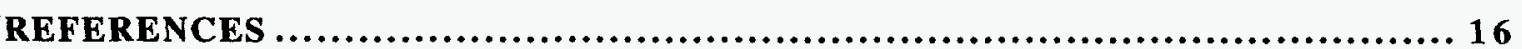

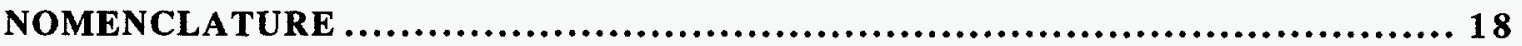

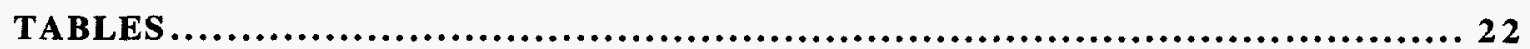

FIGURES......................................................................... 29 


\section{EXECUTIVE SUMMARY}

A Parametric Costing Model has been developed and evaluate as a first step in quantitatively understanding important design options for the Accelerator Production of Tritium (APT) concept. This model couples key economic and technical elements of APT in a two-parameter search of beam energy and beam power that minimizes costs within a range of operating constraints. The costing and engineering depth of the Parametric Costing Model is minimal at the present "entry level" that is intended only to demonstrate a potential for a more-detailed, cost-based integrating design tool. Analytic cost-estimating relationships for key APT subsystems have been calibrated with and benchmarked against more detailed cost estimates of the 3/8-goal APT preconceptual design.

Basecase financial, costing, accelerator, target/blanket, and balance-of-plant parameters are summarized along with the Program of Cost Accounts in Tables I-III. The unit cost of producing neutrons, CON(M\$/mol), and the Total Life-Cycle Cost, TLCC(M\$), are used as object functions with which to measure relative performance as beam power and energy are varied. The well-known tradeoff between accelerator efficiency (high beam current is desirable) and neutron production per proton (high beam energy is desirable) leads to a shallow minimum in CON or TLCC for a given neutron production capacity, YLD(mol/yr) beam power, as beam energy is varied; an optimal beam energy results. This trade off is illustrated in Fig. E1, which illustrates the interplay between neutron-production capacity, beam power, and beam energy; the (shallow) trough of minimum CON is indicated. The variation of CON, TLCC, (optimal) beam energy, and beam power with APT neutronproduction capacity is illustrated in Fig. E2, along the minimum-CON trough depicted in Fig. E1.

The sample results given in Figs. E1 and E2 derive from a single computation of the APT Parametrics Costing Model. Subsequent variations of any of the key input variables listed in Tables I-III give added information on key APT design choices and/or subsystem interactions and tradeoffs. For example, the impact of resistive versus superconducting accelerator structure can be assessed approximated (i.e., within the limitations of the present model) by increasing the shunt resistance along with increasing the accelerator "real-estate" gradient. To counter the strongly positive impacts of these two changes, the unit cost of the accelerator structure is also increased. The resulting impact on the minimum cost (TLCC and CON) and optimal operations (beam energy and beam power) is illustrated in Fig. E3 as a function of optimal neutron-production capacity when the shunt resistance is increased by a factor of $10^{6}$, the real-estate gradient is increased by a factor of 2 , and the unit cost of the accelerating structure is increased by a factor of 1.5. For these conditions, the superconducting option shows an $18 \%$ cost advantage. Relative changes in these costestimating and accelerator-physics factors can obviously enhance or diminish these differences.

Using relatively few parameters and judiciously choosing calibration points, the Parametric Costing Model in a preliminary (rudimentary) form has been created both to benchmark the detailed costing of the preconceptual APT design and to extend, vis-á-vis a two-parameter search in beam-energy/beam-power "space", an understanding of important cost sensitivities. The main goal of this study is to illustrate the versatility and potential of this approach to cost-based design and to suggest a tool for further development and use in future APT engineering designs. For this application to come to fruition, however, the physics, engineering, and costing models reported herein must be enhanced considerably both in intrinsic detail and in connectivity between key disciplines and related subsystems. Example areas where model enhancement or development are needed can be identified with the need to resolve on a cost base the following key issues: 
- superconducting versus copper accelerating structures.

- pulse versus steady-state proton beams.

- target/blanket multiplicity for a given production capacity.

- accelerator multiplicity for a variable and/or staged capacity.

- cost/performance versus accelerator and target/blanket technical, (e.g., power density, beam energy, waste streams, shielding, etc.) connectivity.

The sample results presented in this Executive Summary as well as the evolutionary and applications potential of the APT Parametric Costing Model as an integrated design tool are elaborated. 


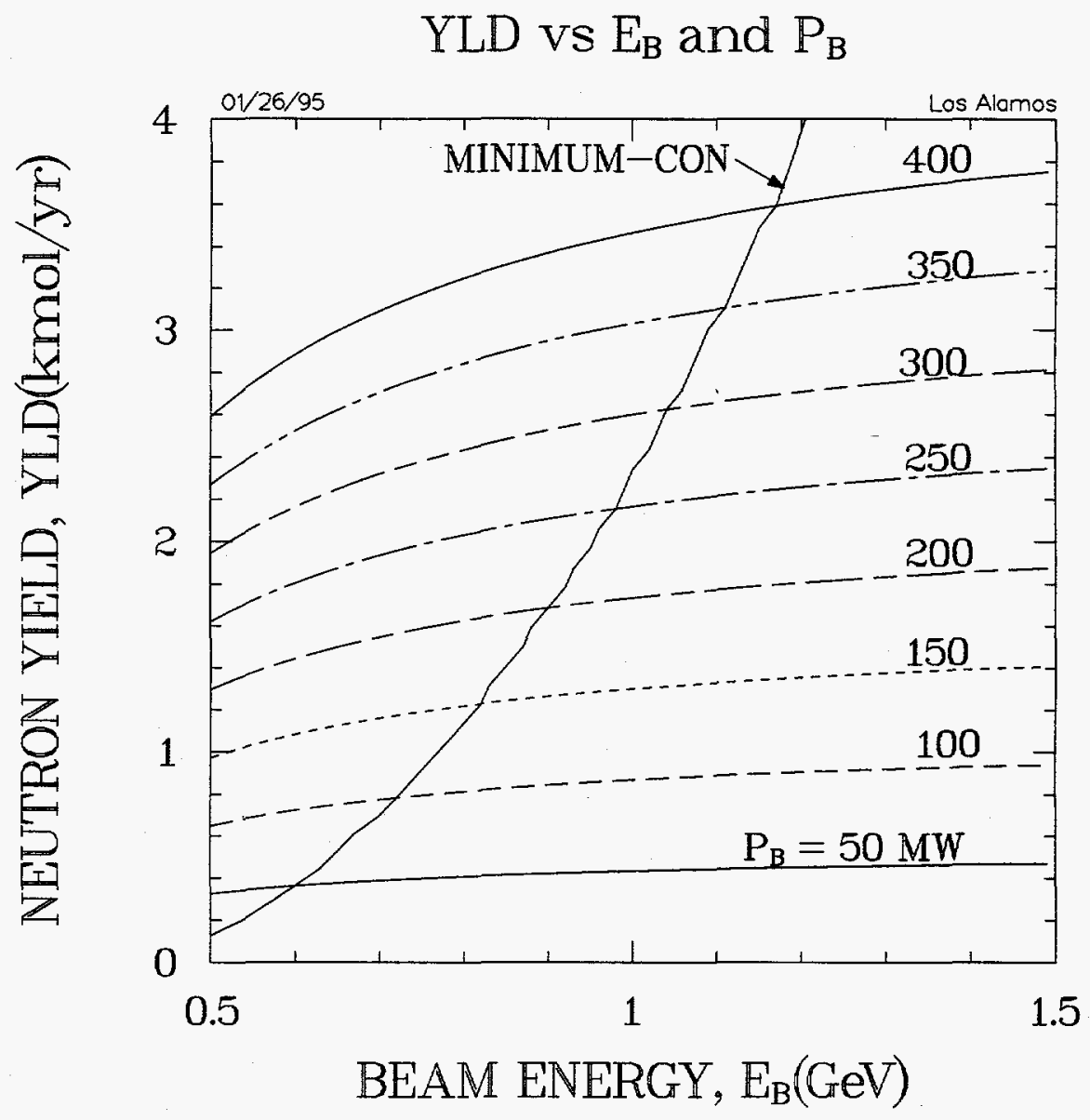

Figure E1. Dependence of facility (rated) neutron-production capacity, on acceleratorbeam energy and power for the Basecase parameters listed in Table III; shown also is the locus of minimum-CON(M $\$ / \mathrm{mol})$ design points; these costminimized designs serve as a basis for subsequent parametric sensitivity studies, albeit, the valley of minimum cost is a shallow one. 


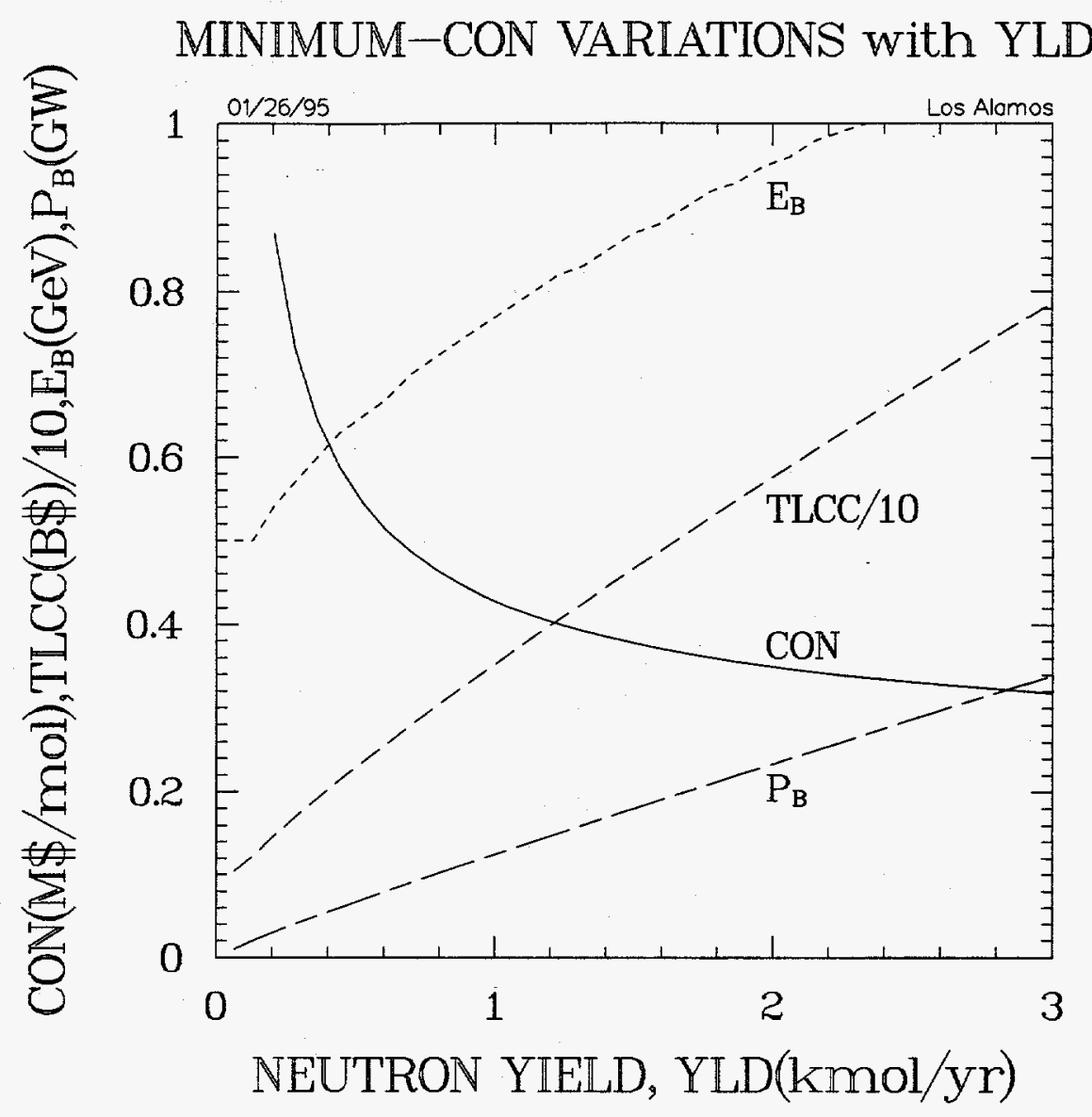

Figure E2. Dependence of unit cost of neutrons, CON(M $\$ / \mathrm{mol})$, and Total Life-Cycle Cost, TLCC(M\$), on machine neutron-production capacity, YLD(mole/yr), for parameters constrained to the value of minimum CON indicated on Fig E1.; the accelerator beam power and energy corresponding to these conditions are also shown. 


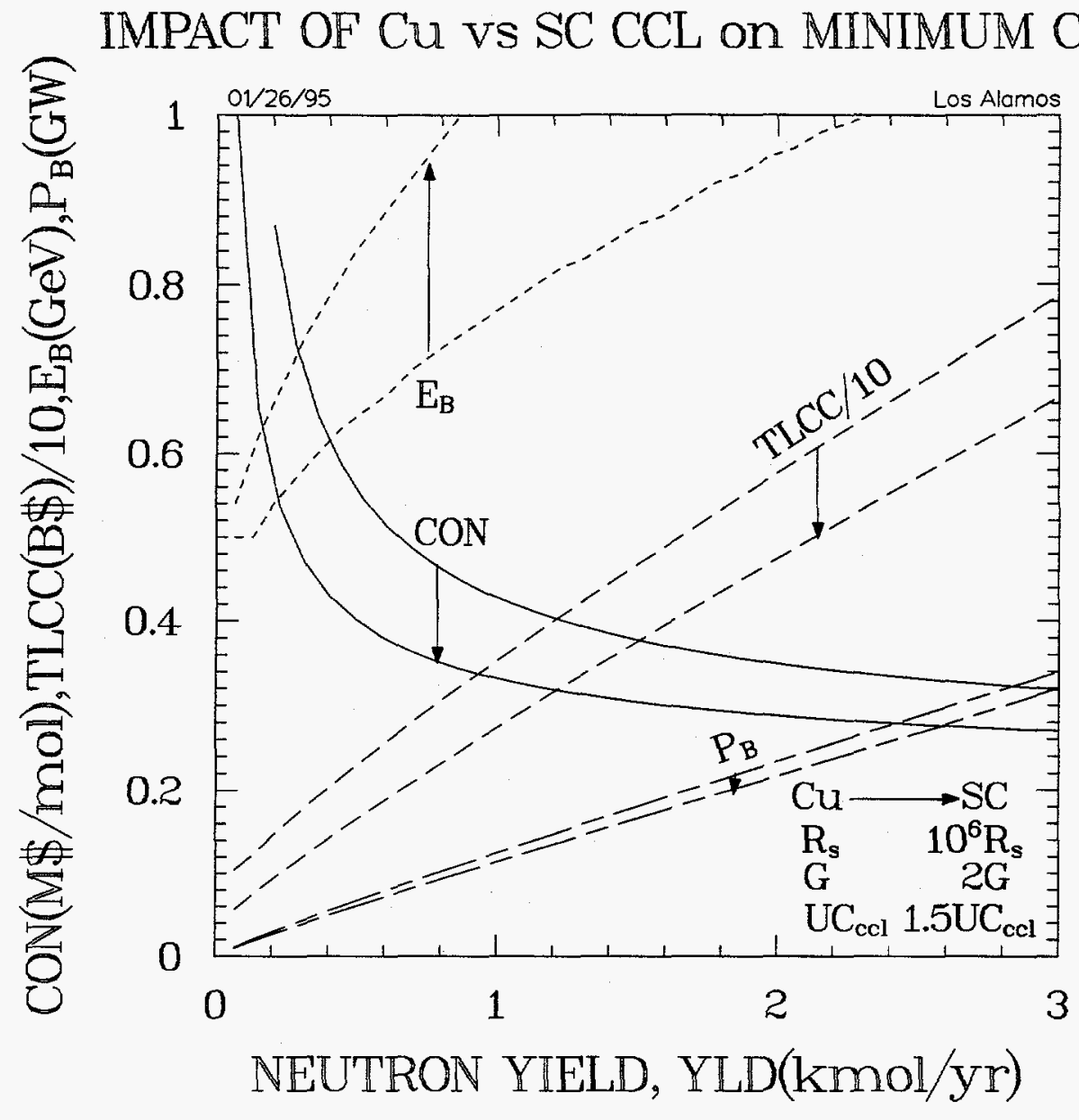

Figure E3. Comparison of resistive $(\mathrm{Cu})$ and superconducting $(\mathrm{SC}) \mathrm{CCL}$ options on the basis of cost for the assumptions indicated: shunt resistance, $R_{s}$, increased by $10^{6}$; "real-estate" gradient, $\mathrm{G}$, increased by 2 ; and $\mathrm{CCL}$ unit cost, $\mathrm{UC}_{\mathrm{CCL}}$, increased by 1.5 . 


\section{INTRODUCTION}

The main technical features of the Accelerator Production of Tritium (APT) concept are described in Refs. 1-4, and a preconceptual cost and schedule based on this point design has been generated. These preliminary APT cost estimates have been made using a standard accounting system ${ }^{6}$ that represents an evolution from and expansion of the NUS Corporation Code of Accounts developed over 25 years ago $^{7}$. Use of this Energy Economics Data Base (EEDB) Program Code of Accounts ${ }^{6}$ allows common-base comparisons to be made between advanced nuclear systems, and for this reason has been adopted in rudimentary form to investigate parametric cost trade offs ${ }^{8}$ associated with netpower produced in conjunction with the Accelerator Transmutation of (nuclear) Waste (ATW) concept ${ }^{9}$. While developed to make comparisons on a common basis of levelized "busbar" power-generation costs using the methodology reported in Ref. 10 and elaborated and modernized in Ref. 11, the flexibility and comprehensiveness of the EEDB system and methodology has led to the adoption of this Code of Accounts for the evaluation of ATW ${ }^{8,9}$ and $\mathrm{APT}^{1-5}$. While other Program Code of Accounts have been use to assess $\mathrm{APT}^{5}$, only the EEDB Code of Accounts, as modified to accommodate unique features of $\mathrm{APT}^{5}$, will be followed in the development and evaluation of the cost-base parametric systems model reported here. The "top-level" EEDB cost accounts, and the key modifications made in adapting it to meeting the needs of the APT optimization are listed in Table I.

The cost estimate of the APT preconceptual design is reported in Ref. 5 down two levels below the main account codes listed in Table I; in some cases, accounting to one or two levels below the detail reported in Ref. 5 was necessary. A comprehensive point design of APT is necessary to resolve this level of detail, as is required by the near-term posture and goal of APT. In the course of developing an in-depth preconceptual design within the compressed time frame established by need and competition, educated but quantitatively unoptimized technical decisions had to be made; the real demands of pushing the APT engineering design in the allotted time to a level of detail required by the preconceptual cost estimate disallowed a systematic and parametric evaluation of the cost and operational impact of choices made for key system parameters, particularly for the accelerator and for the target/blanket system.

Without the level of technical and costing detailed provided by the present APT design ${ }^{1-5}$, the development and implementation of a comprehensive cost-base engineering systems model would not be quantitatively productive beyond the qualitative function provide by simpler parametric ${ }^{8}$ or analytic models ${ }^{12}$. The existence of the present APT point design, and the likelihood of others emerging in the near term, suggests a potential benefit from a more detailed and benchmarked cost-base engineering systems model for APT in providing quantitative design guidance and in replying to the inevitable "what if" questions raise by APT funders, reviewers, customers, and critics. Using a "mappable" condensation of the EEDB Program Code of Accounts, Ref. 5, and a linear scaling of the cost information generated by that point design, the beginning of such a cost-based parametric engineering model is reported herein. It is emphasized that such a model is intended to provide shortturnaround design guidance and answers to technical and economic inquiries, and the efficacy to these guidance and responses will ultimately depend on the level of physics, engineering, and costing detail, as well as the degree of coupling and realism instilled in the 
final tool; the present model is intended only to suggest a direction where these goals may be met.

The basis of the APT Parametric Costing Model is described in Sec. II., which after an overview summarizes financial, engineering, and costing components of the model. A single sample result of the beam energy-power search algorithm, along with a benchmark with the Ref.-5 cost estimate is given in Sec. III. This section also includes sample exercises that examine on the basis of cost the issues of resistive versus superconducting and cost-of-electricity versus plant availability. Section IV. concludes with a brief statement of future work needed to advance the Parametric Costing Model to an integrating design tool for APT.

\section{MODEL}

\section{A. Overview}

The essential elements of the cost-based parametric systems model, be the evaluation analytic $^{12,13}$ or numerical ${ }^{8,14}$, is embodied in the independent variation of the accelerator beam energy, $E_{B}(M e V)$, and beam power, $P_{B}=I_{B} E_{B}$, where $I_{B}(A)$ is the (total) beam current. While the cost-optimizing search algorithm varies $I_{B}$ and $P_{B}$, the main product of the system is neutrons produced at a rate $\mathrm{YLD}(\mathrm{mole} / \mathrm{yr})$, or a derivative product like tritium $^{1-5}$ or fission power. ${ }^{8,14}$ The neutron capacity, however, is directly determined by $P_{B}$ and $I_{B}$, since for a given yield of neutrons per proton, $Y(n / p), Y L D \sim P_{B}\left(Y / E_{B}\right)$. Hence, the $E_{B}-P_{B}$ variation for a given (fixed) target characterization is equivalent to an $E_{B^{-}}$ YLD variation.

For each $\mathrm{E}_{\mathrm{B}}-\mathrm{P}_{\mathrm{B}}$ parameter pair, costs of each of the top-level subsystems depicted in Fig. 1 and listed in Table I are estimated using Cost Estimating Relationships (CERs) that relate the direct cost of developed and installed subsystems to key measures of subsystem capacity or size. An analytic approach ${ }^{12,13}$ of necessity is limited in the extent to which subsystems are included in the estimate of the Total Direct Cost (TDC); while more extensive in cost-estimation detail, the numerical approach at the present level of development ${ }^{8,14}$ cannot match the comprehensiveness of a cost estimate based on a detailed

point design 5 . The numerical evaluation reported herein for APT follows the approach described in Refs. 8 and 14, with modifications and adjustments to the CERs being made on the basis of linearly scaling the results of the recent APT point design 5 , where appropriate. Financial, engineering, and costing bases and assumptions are summarized in the following three subsections.

\section{B. Financial}

Figure 2 re-expresses the systems diagram given in Fig. 1 in terms of the EEDB Program of Cost Accounts ${ }^{11}$. For the present APT application, however, a fission-enhanced Target/Blanket (T/B) is not used, and conversion of the power recovered in the T/B system is not planned; hence, the Turbine Plant Equipment (TPE) Account 23. is zeroed. Furthermore, the Chemical Plant Equipment (CPE) Account 4. for APT (Refs. 8 and 15 designated Account 27. for the CPE, but for the purposes of this APT study the convention adopted in Ref. 5 is used) is limited primarily to the (relatively minor) costs associated with 
the Tritium Extraction Facility (TEF), as well as the processing and disposal of T/B spallation and activation products. The aggregation of the subaccounts under each EEDB top-level account (Table I), as applied in the Ref.-5 study, for use in the present study is described in this subsection. This aggregation is far from perfect, but the goal here is to formulate a rudimentary, but workable, parametrics model that retains a level of physics, engineering, and economics connectivity that is adequate to determined whether a more indepth adaptation of the Ref.-5 (or any follow-on document) detail is useful and warranted.

This subsection describes the formulism used to aggregate and manipulate cost accounts to generate bottomline costs that are relevant to a "top-level" evaluation and optimization of APT; details of the CERs used in this evaluation are found in a subsequent Sec. II.C. First the direct cost for each APT subsystem is estimated, the TDC is determined, and the Indirect Charges designated by the factor $\mathrm{IDC}_{1}$ on Table I are added to give to Total Cost (TC). Initial Spare Component Replacement (SCR) costs are included in TDC. The addition of costs associated with Project Management and Administration (M\&A), Engineering and Design (E\&D), and overall Project Contingency (CONT) charges related to added costs needed to assure Project technical success within given confidence limits (e.g., greater confidence implies greater Project Contingency charges) gives the Total Estimate Cost (TEC); the added E\&D and M\&A charges are considered here as an added Indirect Charge that is designated by the factor $\mathrm{IDC}_{2}$, whereas CONT is a Project-wide contingency charge that is above and beyond any local subsystem contingencies assumed here to be embedded, through the appropriate CER, into TDC (and TC). As indicated on Table I, the factors IDC 1,2 and CONT are derived from the Ref.-5 analysis and used in the APT Parametrics Costing Model.

Addition of Preoperational Costs (PREOPS; Development, Startup, Concept Design, ES\&H Permits, and a separate M\&A charge, all expressed as a fractions of TDC or TC) to TEC gives the Total Project Cost (TPC). An up-front outlay for Decontamination and Decommissioning charges (D\&D, also expressed as a fraction of TDC or TC) is assessed and, as in the Ref-5 formulism, is not included in TPC. For purposes of the parametric model, the up-front $D \& D$ charge (actually, a lesser amount of $D \& D$ should be put into an interest-bearing escrow account) is added to TEC when assessing that component of the Total Life-Cycle Cost, TLCC(M\$).

For a given profile of annual Capital Flow, $\mathrm{CF}(\mathrm{M} \$ / \mathrm{yr})$, up to the time of plant operation (CY2008 assumed in Ref. 5) and cost of money (in unescalated or constant dollars), COM(1/yr), TPC is discounted to a reference year (CY1993 assumed here, as in Ref. 5) using a Normalized Net Present Value factor, NNPV = NPV/TPC, where NPV is the Net Present Value of TPC for a given CF profile and the D\&D cost is included here in TPC. Figure 3 gives the CF profile used in this model and a comparison with that applied in Ref. 5. Once the NPV of all annual Operating and Maintenance (O\&M) charges are determined over the life of the APT facility, $\mathrm{T}_{\mathrm{LIF}}=40 \mathrm{yr}$, the total NPV of TPC and O\&M is listed as the Total Life-Cycle Cost, TLCC(M\$). While different COM values can be used to determine the NPVs of TPC and O\&M, for the purpose of this analysis COM $=0.041 / \mathrm{yr}$ for both.

Four main (constant-dollar) annual charges, $\mathrm{AC}_{\mathrm{j}}(\mathrm{M} \$ / \mathrm{yr})$, are identified: ${ }^{5}$ Staffing, O\&M Consumables, Process Consumables, and Utilities [primarily electric power purchased at a site-dependent Cost-of-Electricity rate $\mathrm{COE}(\mathrm{mil} / \mathrm{kWh})$, which, following Ref. 5, is taken as $66.5 \mathrm{mil} / \mathrm{kWh}$ ]. Assuming that the sum of these annual charges, AC(M $\$ / \mathrm{yr})$, remains constant over the operational time period, $\mathrm{T}_{\mathrm{LIF}}$, the contribution of annual O\&M charges to the TLCC is expressed as $\mathrm{AC} /<\mathrm{CRF}\rangle$, where $<\mathrm{CRF}>(1 / \mathrm{yr})$ is an effective Capital 
Recovery Factor ${ }^{11}$ that expresses all constant-dollar annual charges in terms of a reference year (CY1993) for a given COM. Hence, the Total Life-Cycle Costs of APT is given by

$$
\operatorname{TLCC}(\mathrm{M} \$)=[\mathrm{NNPV}] \times[\mathrm{TPC}]+[\mathrm{AC}] /<\mathrm{CRF}\rangle .
$$

The merit to the TLCC parameter rests primarily in providing a relatively unambiguous comparative parameter for both intra- and inter-device cost-based technology assessments and optimizations; the value of TLCC in setting broadened end-use financial priorities is limited, however. Another more tangible economic Figure of Merit (FOM) is the unit Cost of Product (COP), which in case of APT is tritium for use in nuclear weapons, or the neutrons that with some efficiency, TPN[tritons/(target)neutron], are converted to tritium. For the purposes of this analysis, the Cost of Neutrons, CON(M\$/mol), is adopted as a unit-cost FOM. Two ways to define CON can be envisaged and are evaluate.

First is a simple ratio of TLCC and the total quantity of neutrons produced over the life of the APT plant, YLD pfTLIF, where $\mathrm{p}_{\mathrm{f}}$ is the plant capacity factor and YLD(mole/yr) is the rated (e.g., "name-plate") production capacity. Hence,

$$
\begin{aligned}
& \mathrm{CON} *(\mathrm{M} \$ / \text { mole })=\frac{\mathrm{TLLC}}{\mathrm{YLD} \mathrm{p}_{\mathrm{f}} \mathrm{T}_{\mathrm{LIF}}} \\
& \mathrm{YLD}(\mathrm{mole} / \mathrm{yr})=\beta\left(\mathrm{Y} / \mathrm{E}_{\mathrm{B}}\right) \mathrm{P}_{\mathrm{B}},
\end{aligned}
$$

where the constant $\beta=[\mathrm{SPY}] / \mathrm{e} / \mathrm{N}_{\mathrm{A}}=327 \mathrm{MeV}(\mathrm{mol} / \mathrm{yr}) / \mathrm{MW}, \mathrm{SPY}=3.15 \times 10^{7} \mathrm{~s} / \mathrm{yr}, \mathrm{e}=$ $1.602 \times 10^{-19} \mathrm{MJ} / \mathrm{MeV}, \mathrm{N}_{\mathrm{A}}=6.023 \times 10^{23}$ entities/mole, and the target neutron yield per incident proton, $\mathrm{Y}(\mathrm{n} / \mathrm{p})$, is approximated by the following off-set linear function of beam energy:

$$
\mathrm{Y}(\mathrm{n} / \mathrm{p})=\frac{\mathrm{E}_{\mathrm{B}}-\mathrm{E}_{\mathrm{B}}^{\mathrm{o}}}{\mathrm{y}} ;
$$

typically ${ }^{15}$, the fitting parameters are $E_{B}^{0} \sim 200-210 \mathrm{MeV} / \mathrm{p}$ and $\mathrm{y} \sim 30-35 \mathrm{MeV} / \mathrm{n}$.

A second way to evaluate the unit cost of neutrons produced from the APT accelerator is to express the Total Project Cost, TPC, as an (constant-dollar) annual charge through a Fixed Charge Rate, FCR(1/yr), and then simply to divide the composite annual charge, $\mathrm{AC}^{*}(\mathrm{M} \$ / \mathrm{yr})=\mathrm{AC}+[\mathrm{FCR}] \times[\mathrm{TPC}]$ by the annual (neutron) production rate, $\mathrm{YLD} \mathrm{p}_{\mathrm{f}}$. In this case,

$$
\mathrm{CON}(\mathrm{M} \$ / \mathrm{mol})=\frac{\mathrm{AC}+[\mathrm{FCR}][\mathrm{TPC}]}{\mathrm{YLD} \mathrm{Pf}}
$$

where FCR is taken as [NNPV] $x<\mathrm{CRF}>$ to assure that the same TLCC value is recovered. Both neutron unit costs are evaluated as a measure product cost; it is easily shown that these two measures of the unit cost of producing neutrons differ by a factor CON/CON ${ }^{*}=$ $[C R F] T_{\mathrm{LIF}}$, which for typical financial parameters amounts a factor of 3-4. Generally, CON is used in the results presented in Sec. III. 
To Table $\mathrm{I}^{11}$ has been added the fractional direct-cost contributions of all top-level EEDB Program of Cost Accounts for APT, as reported in Ref. 5 for the ${ }^{3} \mathrm{He}$-Target/Blanket case. Key financial ratios derived from the Ref. 5 analysis are also shown and explained in the Table-I footnotes; these ratios [e.g., IDC 1,2 , CONT, PREOPS/TC, D\&D/TC, SCR/TDC, O\&M(less utilities)/TC, etc.] are used in the financial analyses performed as part of the evaluation of this cost-based parametrics model of APT. Most of the assumptions and information given in the Table-I footnotes, for reasons of space, are not repeated in the text.

\section{Engineering}

At the present formative stage of the APT Parametrics Costing Model, the engineering models that describe the main subsystems listed in Figs. 1 and 2 contain only the minimal level of detail needed for a preliminary demonstration of the broader approach being suggested here. The accelerator structure, RF power, and associated buildings and structures are prime cost drivers (including the latter items, the accelerator comprises $65.0 \%$ of the ${ }^{3} \mathrm{He} / \mathrm{APT}$ direct cost ${ }^{5}$ ) and, therefore, are described separately below. The remaining APT subsystems are described together after a description of the accelerator model is given.

\section{Accelerator Equipment (Account 27.)}

\section{a. Basic Model}

The parametric model of the Accelerator Equipment is that used in the cost assessment of $\mathrm{ATW}^{8}$ and is depicted in Fig. 4. Power consumed in the generation, transport, and conversion of beam kinetic energy represents a major component of the recirculating power fraction for the power-producing $\mathrm{ATW}^{8}$ and for the tritium-producing APT. The efficiencies $\eta_{\mathrm{DC}}, \eta_{\mathrm{RF}}$, and $\eta_{\mathrm{WG}}$ are associated with the generation and transport of RF power to the accelerator per se. The RF $\rightarrow$ beam coupling efficiency is modeled as $\eta_{B}=$ $1 /\left(1+I^{*} / I_{B}\right)$, where $I^{*}=f_{D} G /\left(R_{S} \cos \phi\right)$ and front-end (RFQ, DTL, and BCDTL or CCDTL) losses are accounted separately. ${ }^{8}$ In the above expression, $\eta_{B}=P_{B} /\left(P_{B}+P_{\Omega}\right)$ is ratio of final beam power to beam plus cavity Ohmic losses, $\mathrm{G}(\mathrm{MV} / \mathrm{m})$ is the "real-estate" accelerating electric-field gradient in the CCL, $\phi$ is the phase angle between beam bunch and accelerating voltage, the nominal (average, effective) RF-cavity shunt resistance is $R_{s}(M V / m)$, and $f_{D}$ is the beam duty factor or ratio of average-to-peak beam current, $\mathrm{I}_{\mathrm{B}} / \mathrm{I}_{\mathrm{B}}^{\mathrm{MAX}}$.

The accelerator model used in the ATW Systems Code (ATWSC) ${ }^{8}$ approximately accounts separately for the front-end (FE) and the CCL losses, following the beam-energy and power splits between RFQ, DTL, BCDTL (or CCDTL), and CCL parts of the accelerator, as is listed in Ref. 16. Figure 4 illustrates this division, with the model described below separating FE into FE1 (RFQ + DTL) and FE2 (BCDTL or CCDTL) components. The efficiency with which RF power is translated into beam power is described by a local (FE1 or FE2) coupling efficiency, $\eta_{\mathrm{B}}^{\mathrm{FEj}}=1 /\left(1+\mathrm{I}_{\mathrm{FEj}}^{*} / I_{\mathrm{B}}\right)$, with the parameters $\mathrm{I}_{\mathrm{FEj}}^{*}(\mathrm{j}=1,2)$ 
being determined from the FE beam and cavity-loss powers report in Ref. 16. These and other parameters for an accelerator model that resolves FE losses are listed in Table II.

Separation of accelerator Ohmic losses into FE = FE1 + FE2 and CCL components leads to the following expression for the ratio of final beam power, $P_{B}=E_{B} I_{B}$, to total $R F$ power delivered to the accelerator cavities:

$$
\eta_{\mathrm{B}}=\frac{1+\mathrm{E}_{\mathrm{B}}^{\mathrm{FE}} / \mathrm{E}_{\mathrm{B}}^{\mathrm{CCL}}}{1 / \eta_{\mathrm{B}}^{\mathrm{CCL}}+\left(\mathrm{E}_{\mathrm{B}}^{\mathrm{FE}} / \mathrm{E}_{\mathrm{B}}^{\mathrm{CCL}}\right) / \eta_{\mathrm{B}}^{\mathrm{FE}}}
$$

where $E_{B}=E_{B}^{C C L}+E_{B}^{F E}, E_{B}^{F E}=E_{B}^{F E 1}+E_{B}^{F E 2}$, and the following expressions give $\eta_{\mathrm{B}}^{\mathrm{CCL}}$ and $\eta_{\mathrm{B}}^{\mathrm{FE}}$ :

$$
\begin{aligned}
& \eta_{\mathrm{B}}^{\mathrm{CCL}}=\frac{1}{1+\mathrm{I}_{\mathrm{CCL}}^{*} / \mathrm{I}_{\mathrm{B}}} \\
& \eta_{\mathrm{B}}^{\mathrm{FE}}=\frac{1+\mathrm{E}_{\mathrm{B}}^{\mathrm{FE} 2} / \mathrm{E}_{\mathrm{B}}^{\mathrm{FE} 1}}{1 / \eta_{\mathrm{B}}^{\mathrm{FE} 1}+\left(\mathrm{E}_{\mathrm{B}}^{\mathrm{FE} 1} / \mathrm{E}_{\mathrm{B}}^{\mathrm{FE} 2}\right) / \eta_{\mathrm{B}}^{\mathrm{FE} 2}},
\end{aligned}
$$

with $\eta_{\mathrm{B}}^{\mathrm{FEj}}=1 /\left(1+\mathrm{I}_{\mathrm{FEj}}^{*} / \mathrm{I}_{\mathrm{B}}^{\mathrm{FEj}}\right)$ and $\mathrm{j}=1,2$, as defined on Fig. 4. The values for the constant coupling parameters are listed in Table II, and the $E_{B}$ dependence of $R_{S}$ for the $\mathrm{CCL}$, as determined by detailed beam-dynamics simulations, ${ }^{16}$ is $R_{s}(\mathrm{M} \Omega / \mathrm{m})=36.70-$ $2,400.0 / \mathrm{E}_{\mathrm{B}}^{\mathrm{CCL}}$. This latter expression is used to determine the shunt resistence, given $E_{B}^{C C L}=E_{B}-E_{B}^{F E}$, or $R_{S}$ is specified directly.

Central to the cost optima determined by the model reported herein is a trade off between accelerator structural costs, accelerator power requirements, spallation-target performance, and (if any) neutron-production enhancement through a (blanket) fission boost. Since these trade offs are generally at the root of the cost projections that emerge from any numerical parametric evaluation, they are briefly explored analytically in the following subsection.

\section{b. Energy Optimization and Scaling}

The length (and cost) of the accelerator structure and tunnel is largely determined by the "real-estate" or average accelerating voltage gradient, G(MV/m). Larger gradients and reduced accelerator size and $\mathrm{RF}$ power consumption can be achieved using superconducting RF cavities, but a yet-to-be-resolved cost trade off exists between these potential cost savings and the added expenses associated with the more-expensive superconducting cavities, the addition of cryogenic refrigeration losses to the "wall-plug" power requirements, and a possibly more difficult (time-consuming) maintenance scheme; albeit, a trade off between Mean-Time-To-Failure (MTTF) and Mean-Time-To-Repair (MTTR) must be resolved. For the copper-cavity APT design, however, a clear cost trade exists between increased RF power (decreased $\eta_{B}$ ) and decreased CCL structure as the real-estate gradient is increased. This "local" optimization for a system with RF-power unit 
costs $\mathrm{UC}_{\mathrm{RF}}(\mathrm{M} \$ / \mathrm{MW})$ and $\mathrm{CCL}$ unit cost $\mathrm{UC}_{\mathrm{CCL}}(\mathrm{M} \$ / \mathrm{m})$ suggests an optimum real-estate gradient given by

$$
\mathrm{G}_{\mathrm{opt}}(\mathrm{MV} / \mathrm{m})=\sqrt{\mathrm{UC}_{\mathrm{CCL}} \mathrm{R}_{\mathrm{s}} / \mathrm{UC}_{\mathrm{RF}}} .
$$

The real-estate gradient is either determined from this expression or is specified independently.

For any application where a high power accelerator is used to produce neutrons, minimization of the "wall-plug" energy invested in each neutron is an important objective. Defining $E_{n}(M e V / n)=P_{E A} / I_{n}$, where $I_{n}(n / s)=Y_{B} / e$ is the primary target neutron source strength, and using the off-set linear representation for the target neutron yield per proton, $\mathrm{Y}(\mathrm{n} / \mathrm{p})$, given by Eqn. (4), with the total accelerator electric-power requirement given by $P_{E A}=P_{B} /\left(\eta_{D C} \eta_{R F} \eta_{W G} \eta_{B}\right)$, the following expression for $E_{n}$ results:

$$
E_{n}(\operatorname{Mev} / n)=\frac{y}{\eta_{D C} \eta_{R F} \eta_{W G}} \frac{E_{B} / E_{B}^{o}+\left(P_{B} / P^{*}\right)\left(E_{B} / E_{B}^{o}\right)^{2}}{E_{B} / E_{B}^{o}-1},
$$

where $\mathrm{P}^{*}(\mathrm{MW})=\mathrm{I}^{*} \mathrm{E}_{\mathrm{B}}^{\mathrm{O}}$ is a design parameter that characterizes both the accelerator (i.e., $\mathrm{I}_{\mathrm{B}}^{*}$ ) and target (i.e., $\mathrm{E}_{\mathrm{B}}^{\mathrm{o}}$ ). Equation (10) is plotted on Figure 5 for $\mathrm{f}_{\mathrm{D}}=1.0$, and illustrates the optimum energy cost to produce a neutron resulting from the balance for a given capacity, $P_{B}$, between increased $E_{B}$ (increased neutron yield per proton) and reduced $E_{B}$ (increased $I_{B}$ and increased $\eta_{B}$ ). For a given beam power, accelerator $(C C L)$ structure, and target-yield characteristics $\left(\mathrm{E}_{\mathrm{B}}^{\mathrm{o}}, \mathrm{y}\right)$, the minimum "wall-plug" energy invested per source neutron occurs at the following beam energy and has the following value, respectively:

$$
\begin{aligned}
& \left(\mathrm{E}_{\mathrm{B}} / \mathrm{E}_{\mathrm{B}}^{\mathrm{o}}\right)_{\min }=1+\sqrt{1+\mathrm{P}_{\mathrm{B}} / \mathrm{P}^{*}} \\
& \frac{\left(\mathrm{E}_{\mathrm{n}}\right)_{\min }}{\left(\mathrm{E}_{\mathrm{n}}\right)_{\infty}}=1+\frac{2\left(1+\sqrt{1+\mathrm{P}_{\mathrm{B}} / \mathrm{P}^{*}}\right)}{\mathrm{P}_{\mathrm{B}} / \mathrm{P}^{*}} .
\end{aligned}
$$

For the typical accelerator efficiencies and target parameters suggested above, $\left(E_{n}\right)_{\infty}=$ $\mathrm{y} /\left(\eta_{\mathrm{DC}} \eta_{\mathrm{RF}} \eta_{\mathrm{WG}}\right)=94 \mathrm{MeV} / \mathrm{n}$ and $\mathrm{P}^{*}=5.7 \mathrm{f}_{\mathrm{D}} \mathrm{MW}$.

The decrease in the minimum $\mathrm{E}_{\mathrm{n}}(\mathrm{MeV} / \mathrm{n})$ with increasing beam energy is accompanied by a decrease in the peak-to-average current, $\mathrm{f}_{D}=\mathrm{I}_{B} / \mathrm{I}_{B}^{\mathrm{MAX}}$, and, hence, increased demands on the injector(s), local accelerating structure, and accelerator electrical equipment (e.g, energy store). The link between the cost of operation with $\mathrm{f}_{\mathrm{D}}<1$ and increased RF $\rightarrow$ beam energy coupling efficiency, $\eta_{B}$, remains an important but inadequately resolved issue; for the purposes of this analysis, $f_{D}$ is taken as unity. Additionally, for the cases reported here, only $E_{B}^{\mathrm{FE}}=E_{B}^{\mathrm{FE} 1}+E_{B}^{\mathrm{FE} 2}(=80 \mathrm{MeV})$ is specified so that the dependence of $R_{s}$ on 
$E_{B}^{C C L}$ listed above can be evaluated. Even then, for most of the cases reported here, $R_{s}$ is taken as a constant.

\section{Other Subsystems}

All other ATP subsystems listed on Table I are presently described in the Parametric Costing Model at a level the boarders on the superficial. While considerable future work is needed to translate the ongoing APT point-design efforts into a parametric form that can be used with confidence in the Parametric Costing Model, it should be noted that the Accelerator Equipment Account 27. and that part of the Structures and Improvements Account 21. related directly to the Accelerator Equipment comprise $65.0 \%$ of the TDC. Also, the $10.2 \%$ contribution to TDC made by the Reactor Plant Equipment Account 22., is comprised to an extent of $79.8 \%$ by the Target/Blanket subsystems; after the Accelerator, the Target/Blanket model used in the parametrics model is deserved of increased engineering resolution.

The following subsections summarize the status of each of the remaining cost accounts being evaluated for use in APT the Parametric Costing Model. When appropriate, past practices applied to the ATW economic assessment ${ }^{8,14}$ are described. All Cost Estimating Relationship (CERs) used pertain only to the Total Direct Cost (TDC), on which the "operators" described in Sec. II.A. are used in the conversion to Total Cost (TC), Total Estimated Cost (TEC), Total Project Cost (TPC), and, ultimately, to Total Life-Cycle Cost (TLCC), Annual Charges [AC(M\$/yr)], and the unit Cost of Neutrons, CON or CON*(M\$mol). The (initial) cost for Spare Component Replacements (SCRs) for each subsystems is taken as a variable ${ }^{8}$ fraction of the direct cost for that subsystem; in the present case, a straight $2.8 \%$ of TDC for (initial) spares is used. ${ }^{5}$

\section{a. Structures and Site Improvements (Account 21.)}

Only the accelerator tunnel is costed on the base of size (length). All other building and structures costs are estimated as a fraction of the direct capital cost of equipment and subsystems housed within and/or supported by those building and structures. These ratios of building/structures costs to the relevant direct capital costs are derived from the Ref.-5 point design or conceptual designs of nuclear power plants. Incorporation of more engineering detail will allow each (main) building to be estimate in size, and, based on its function, a cost per unit of floor area or building volume applied to obtain an improved cost estimate.

\section{b. Reactor Plant Equipment (Account 22.)}

For the APT the Reactor Plant Equipment subsystem is comprised primarily of the Target/Blanket and the Primary and Secondary Heat-Transport Systems. The Ref.-5 preconceptual cost estimate suggests that the cost of the Target/Blanket subsystem is $79.8 \%$ of Account 22. The ATW costing algorithm ${ }^{8}$ used for the Target/Blanket subsystem specified a thermal Mass Power Density, MPD(MWt/tonne), and a corresponding unit cost, $\mathrm{UC}_{\mathrm{TAR} / \mathrm{BLK}}(\$ / \mathrm{kg})$, for the designed, fabricated, and installed system. A recent study of a molten-salt ADEP concept ${ }^{14}$ elevated this parametrization to a level that allowed the size of key Target/Blanket components (e.g., target per se, moderator, molten-salt coolant, neutron reflector, reactor vessel) to be estimated in conjunction with key neutronics and thermal-hydraulic constraints; specification of appropriate unit costs for each appropriately sized component, $\mathrm{UC}_{\mathrm{j}}(\$ / \mathrm{kg})$, allowed a more realistic cost estimate to be made. The direct 
costs for the (economically less-important, aside from issues of TPN and availability) APT Target/Blanket subsystem is presently made on the basis of beam power by specifying a unit cost, $\mathrm{UC}_{\mathrm{TAR} / \mathrm{BLK}}[\$ / \mathrm{W}($ beam $)]$, derived from the preconceptual APT costing exercise .

The Primary Heat-Transport (PHT) system for the APT is similarly costed on the basis of beam power using a Ref.-5 calibrated unit cost, $\mathrm{UC}_{\mathrm{PHT}}[\$ / \mathrm{W}($ beam $)]$. This unit cost is assumed to include any Secondary Heat-Transport (SHT) system. More detailed scaling of Primary Heat-Transport systems with thermal power are available; an example of a highly aggregated CER for a high-performance (temperature) nuclear-power system is ${ }^{8,17}$

$$
\mathrm{UC}_{\mathrm{PHT}}(\$ / \mathrm{Wt})=\frac{0.80}{\left[\mathrm{P}_{\mathrm{TH}}(\mathrm{MWt})\right]^{0.45}},
$$

but this expression is applicable only for large $\left(\mathrm{P}_{\mathrm{TH}}>2-3,000 \mathrm{MWt}\right)$ systems.

These Primary and Secondary Heat-Transport systems as assumed to support only the Target/Blanket subsystem; a (low-grade) thermal-heat removal system is costed separately as part of the Accelerator Equipment and added to Account 27.

c. Turbine Plant Equipment (Account 23.)

The fractional-goal APT is expected to find cheaper electrical power outside its boundaries rather than to invest in Turbine Plant Equipment and enhanced Primary Heat-Transport, Electric Plant Equipment, and Miscellaneous Plant Equipment with which to collect, convert, and distribute the needed in-house electrical power. Typical scaling of Turbine Plant Equipment costs with the gross electric power, $\mathrm{P}_{\mathrm{ET}}(\mathrm{MWe})$, is given below ${ }^{8,17}$

$$
\mathrm{UC}_{\mathrm{TPE}}(\$ / \mathrm{We})=\frac{0.67}{\left[\mathrm{P}_{\mathrm{ET}}(\mathrm{MWe})\right]^{0.17}}
$$

Again, this TPE unit cost scaling applies to system capacities that are generally larger $(>1,000 \mathrm{MWe})$ than the electrical needs of a fractional-goal APT.

\section{d. Electric Plant Equipment (Account 24.)}

Only $\sim 5.8 \%$ of the TDC reported for $\mathrm{APT}^{5}$ goes to the Electric Plant Equipment. For larger $(\sim 1,000-\mathrm{GWe})$ nuclear power stations the following expression ${ }^{8,17}$ is used to estimate the unit cost of this account:

$$
\mathrm{UC}_{\mathrm{EPE}}(\$ / \mathrm{We})=\frac{3.71}{\left[\mathrm{P}_{\mathrm{ET}}(\mathrm{MWe})\right]^{0.51}}
$$

For the purposes this APT parametrics model, $\mathrm{UC}_{\mathrm{EPE}}$ is scaled directly (and linearly) from the Ref.-5 study. The Electric Plant Equipment so costed is assumed to be "globally" needed throughout the APT complex; an Electric Plant Equipment associated directly with the accelerator is also computed using a constant unit cost and added to the Accelerator Equipment Account 27. 
The APT Miscellaneous Plant Equipment accounts for even less $(\sim 4.1 \%)$ of the TDC than the Electric Plant Equipment. As for the PHT, TPE, and EPE systems, CERs for larger system of the form given below ${ }^{8,17}$ can be used

$$
\mathrm{UC}_{\mathrm{MPE}}(\$ / \mathrm{We})=\frac{0.87}{\left[\mathrm{P}_{\mathrm{ET}}(\mathrm{MWe})\right]^{0.49}}
$$

For the purposes this APT parametrics model, $\mathrm{UC}_{\mathrm{MPE}}$ is scaled directly (and linearly) from the Ref.-5 study.

\section{f. Main Condenser Heat Rejection (Account 26.)}

While of sufficient economic importance in a nuclear power station for the EEDB Program of Cost Accounts ${ }^{11}$ to elevate this system to the status of a major account, for APT the Heat Rejection system amounts to only $2.1 \%$ of TDC. For the purposes of this APT parametrics model, $\mathrm{UC}_{\mathrm{HTR}}(\$ / \mathrm{Wt})$ is scaled directly (and linearly) from the Ref.-5 study in proportion to the total thermal power rejected from the APT (e.g., all accelerator input power at full capacity, $P_{E A}$, and all non-accelerator auxiliary power, $P_{A U X}=f_{A U X} P_{E A}$. The auxiliarypower fraction of a nuclear power station of total electrical capacity $\mathrm{P}_{\mathrm{ET}}(\mathrm{MWe})$ is typically $f_{A U X}=0.02-0.03$; on the basis of the Ref.-5 APT point design, $f_{A U X}=0.11$ when expressed in terms of the total accelerator power only. It is noted that if the APT accelerator were driving an electric power station through a high-muliplication blanket with a recirculating power to the accelerator of $\mathrm{P}_{\mathrm{EA}} / \mathrm{P}_{\mathrm{ET}} \sim 0.20$, then the value of $\mathrm{f}_{\mathrm{AUX}}$ would be $\sim 0.02$, which is in line with power-plant experience.

\section{g. Chemical Plant Equipment (Account 4.)}

While the Chemical Plant Equipment subsystem for APT embodies primarily the Tritium Extraction Facility and, according to the Ref.-5 study, amounts to only $3.6 \%$ of the projected TDC, in the broader context of a net-power-generating, transmuting $\mathrm{ATW}^{8}$, Account 4. (Account 27. in the ATW Program of Cost Accounts) corresponded to 38.5\% of the TDC projected for that 1,560 MWe(net) system that burned the actinides and longlived fission products from 6.1 1,000-MWe Light Water fission Reactors (LWRs). The following CER based on a chemical plant processing $\mathrm{R}_{\mathrm{HM}}(\mathrm{kg} / \mathrm{yr})$ of heavy metal ${ }^{18}$ was used $^{8}$

$$
\mathrm{UC}_{\mathrm{CPE}}(\mathrm{M} \$ / \mathrm{kg} / \mathrm{yr})=\frac{9.4}{\mathrm{R}_{\mathrm{HM}}^{0.6}},
$$

where, as for some of the previously listed unit-cost scalings, this CER corresponds to fairly large plants. The tritium plant in $\mathrm{ATWSC}^{8}$ is costed at a constant $25 \mathrm{M}$; the Tritium Extraction Facility direct cost for the ${ }^{3} \mathrm{He}$ APT was estimated ${ }^{5}$ to be $39.3 \mathrm{M} \$$. For the purpose of the APT Parametric Costing Model, the Tritium Extraction Facility direct cost is scaled linearly with beam power, $\mathrm{P}_{\mathrm{B}}$, using the Ref.-5 costing to generate the unit cost, $\mathrm{UC}_{\mathrm{CPE}}([\$ / \mathrm{W}($ beam $)]$. 


\section{Costing}

When combined with a specific set of Cost Estimating Relationships (CERs), the financial and engineering models described in the previous two subsections are evaluated parametrically in $E_{B}$ and $P_{B}$. As noted in the introduction, this variation is equivalent to an $\mathrm{E}_{\mathrm{B}}$-YLD variation, where the neutron ("name-plate") production capacity is YLD $\mathrm{P}_{\mathrm{B}}\left(\mathrm{Y} / \mathrm{E}_{\mathrm{B}}\right)$. The TEC $(\mathrm{M} \$)$, TLCC $(\mathrm{M} \$)$, and $\mathrm{CON}(\mathrm{M} \$ / \mathrm{mol})$ parameters, derived form the procedures outlined in Sec. II.A., are used as "object functions" with which to examine the impacts of key physics, engineering, operational (RAMI and ES\&H), and economic assumptions. Table III. lists key inputs to the APT Parametric Costing Model. These parameters reflect the assumptions made in and scaling derived from the present APT preconceptual design $^{1-5}$, as described in Sec. II.B. As reflected in Table III and the footnotes attached thereto, the APT Parametric Costing Model presently is at a minimal level of fidelity, particularly with respect to resolving the connectivity between the abovementioned physics, engineering, operational (RAMI and ES\&H), and economic issues. However, with improving physics, engineering, and costing scaling relationships generated in conjunction with the ongoing APT point designs, a useful tool for designintegrated parametric systems analyses can be evolved.

\section{RESULTS}

The main goal of the analyses reported herein is to present a single example of the APT Parametric Costing Model, using the fixed input listed on Tables I-III, for the purposes of setting priorities in enhancing the fidelity of this prospective design tool through more detailed benchmarking with existing and ongoing APT point designs and through enhancement of key physics, engineering, and costing models. First, one sample of a parametric $E_{B}-P_{B}(Y L D)$ variation is given for the basecase parameters listed in Tables I-III; in the course of this single run, information on the scaling of cost with capacity, as measured either by beam power or neutron production, is automatically generated. Secondly, the APT Parametric Costing Model is used to examine two important issues for APT: a) the cost impact of resistive-copper versus superconducting CCL accelerating structure; and b) operating cost versus capital cost trade offs vis a vis a given load curve, $\operatorname{COE}\left(\mathrm{p}_{\mathrm{f}}\right)$.

For any set of input parameters, the cost-scaling with size and capacity exhibits certain generic features that reflect a trade between accelerator capital cost and operating cost; this trade is inherent to the acceleration and neutron-production scheme forming the basis of the APT concept. The capital costs scale both with beam energy and beam power, whereas the main operating cost (i.e., electrical power) scales primarily with beam power. Superposed on this cost connection between beam power and beam energy are the dependencies of neutron-production efficiency, $\mathrm{Y}(\mathrm{n} / \mathrm{p})$, on beam energy [Eqn. (4)] and RF $\rightarrow$ beam powercoupling efficiency, $\eta_{B}$, on beam current [Eqn.(6)]. This interplay results in minimization of "wall-plug" energy required to create a spallation neutron, as is shown in Fig. 5. This rapid fall in energy invested per neutron (and ultimately cost per neutron) at low beam energy is followed by a shallow minimum or near asymptote that results from the increase in $\mathrm{Y}$ and decrease in $\eta_{\mathrm{B}}$ (e.g., decrease in beam current at constant capacity) as $\mathrm{E}_{\mathrm{B}}$ is increased. 
Total cost also shows a strong linear dependence on beam power and capacity that is dominated by the cost of accelerator structure at low power and the cost of electric utilities and RF power as $P_{B}$ is increased. Hence, the total cost per unit beam power, expressed either on a straight $\$ / \mathrm{W}$ bases or on an annual $\$ /(\mathrm{W}$ yr $) \sim \mathrm{M} \$ / \mathrm{mol}$ basis, shows a decrease to an asymptotic value for either unit cost as $\mathrm{P}_{\mathrm{B}}$ is increased. Low-capacity systems deliver a more expensive product simply because of an under-utilized and expensive acceleration structure; pushing more current through this large initial capital investment causes those items that scale in cost with $P_{B}$ to become more important for the larger capacity systems that result. The weak dependence of $\mathrm{Y} / \mathrm{E}_{\mathrm{B}}$, since $\mathrm{YLD} \sim \mathrm{P}_{\mathrm{B}}\left(\mathrm{Y} / \mathrm{E}_{\mathrm{B}}\right)$, renders a non-linearity to the generic scaling that is included in the results presented below.

\section{A. Sample $\mathbf{E}_{\mathbf{B}}-\mathbf{P}_{\mathbf{B}}$ Parametrics Result}

The results from a single survey run of the Parametrics Costing Model are first summarized. The fixed input used to generate these $E_{B}-P_{B}$ parametric results are given in Table III and approximate closely the detailed costing of the preconceptual ${ }^{3} \mathrm{He} / \mathrm{APT}$ pointdesign reported in Ref. 5. A benchmarking comparison with the $P_{B}=200 \mathrm{MW}\left(\mathrm{E}_{\mathrm{B}}=\right.$ $1,000 \mathrm{MeV}$ ) costs is then given in the following Sec. III.A.2.

\section{Parametrics}

For a given set of input parameters (Table III), the Parametrics Costing Model loops through a range of $E_{B}$ and $P_{B}$ values and generates parametric dependencies of machine parameters and costs of the kind given on Fig. 6. For a fixed beam power, increased beam energy and the associated decrease in beam current results in a decrease in the overall accelerator efficiency, $\eta_{A}$, and an increase in RF and electrical power costs as $E_{B}$ increases. In spite of the decreased accelerator structure costs, TDC, TC, TEC, and TPC increase slowly with increasing beam energy. The annual charges associated with both electrical power purchases and other O\&M costs increase to give the increase in $\mathrm{AC}(\mathrm{M} \$ / \mathrm{yr})=$ $\mathrm{AC}_{\mathrm{O} \& \mathrm{M}}+\mathrm{AC}_{\mathrm{ELC}}$ with the increase in $\mathrm{E}_{\mathrm{B}}$ observed in Fig. 6. The net result is an increase in TLCC with $E_{B}$ for a given value of beam power. The unit cost of neutrons, CON or $\mathrm{CON}^{*}(\mathrm{M} \$ / \mathrm{mole})$, however, shows a shallow minimum because of the aforementioned trade of between increased target yield, $\mathrm{Y}(\mathrm{n} / \mathrm{p})$, and increased total annual charge, $\mathrm{AC}^{*}(\mathrm{M} \$ \mathrm{yr})=\mathrm{AC}+\mathrm{AC}_{\mathrm{CAP}}$, or increased $\mathrm{TLCC}(\mathrm{M} \$)$. Figure 7 summarizes the dependence of CON and TLCC on both $E_{B}$ and $P_{B}$. Since $Y L D(m o l / y r) \sim P_{B}\left(Y / E_{B}\right)$, the neutron-production capacity is varying somewhat along each of the constant- $P_{B}$ curves in Figs. 7. When CON and TLCC are plotted versus $\mathrm{E}_{B}$ as lines of constrained YLD on Fig. 8, instead of constrained $\mathrm{P}_{\mathrm{B}}$ (Fig. 7), the (shallow) minimum discussed previously appears: for a given $Y L D$, low values of $E_{B}$ decrease $Y$; high values of $E_{B}$ increase $I_{B}$ and decrease $\eta_{B}$ (for a fixed $f_{D}$ ).

The main product of APT is neutrons and the conversion of those neutrons with some efficiency TPN $(t / n)$ to tritons. The parametric results given on Figs. 6 and 7 have been reformulated and extended into a plot of neutron yield versus $\mathrm{E}_{\mathrm{B}}$ and $\mathrm{P}_{\mathrm{B}}$ on Fig. 9. The locus or "trough" of minimum CON is also indicated. It is emphasized that the capacity 
$\mathrm{YLD}(\mathrm{mol} / \mathrm{yr})$ is the "name-plate" value, with the actual annual production being $\mathrm{YLD}^{\circ}=\mathrm{p}_{\mathrm{f}}$ YLD.

Figure 10 gives the dependence of key system parameters and costs on beam power for the minimum-CON point designs. The increases in TPC(M\$) and AC(M\$/yr) occur for the reasons given in the preamble to this section. The upward drift in the "optimum" beam energy as $P_{B}$ is increased also results from this $Y(n / p)$ versus (capital and operating) cost trade off. The unit cost of accelerator power, $T P C / P_{B}(\$ / W)$, is also depicted on Fig. 10. Lastly, the increase in the overall accelerator efficiency, $\eta_{A}$, with increased $P_{B}$ for these minimum-CON case generally pushes beyond values enforced in the Ref.-5 study, and is a cause for cost (annual-charge) differences reported in the benchmark comparison given in the following subsection. The dependence of the minimum-CON values of CON, TLCC, and $E_{B}$ on neutron production capacity, $Y L D(m o l / y r)$, is given on Fig. 11; the corresponding dependence of beam power is also shown.

The direct-cost breakdown at the level of accounting used in the Parametrics Costing Model is given as a function of $P_{B}$ in Fig. 12. These subsystem direct costs are given as a fraction of TDC(M\$), the magnitude of which is also plotted on Fig. 12. A comparison with the corresponding results from the detailed costing of the ${ }^{3} \mathrm{He} / \mathrm{APT}$ preconceptual design reported in Ref. $5\left(P_{B}=200 \mathrm{MW}, E_{B}=1,000 \mathrm{MeV}\right)$ is given in the following subsection. Generally, the Accelerator Equipment Account 27. (ACC in Fig. 12) for these minimumCON designs is nearly $50 \%$ of TDC; when the cost of the accelerator tunnel is included (the Parametrics Costing Model incorporates this cost in Account 21, which in the parlance of Fig. 12 is BLD), the accelerator comprises nearly $60 \%$ of TDC for these minimum-CON cases.

\section{Benchmark 5}

Table IV gives a comparison of the Parametrics Costing Model cost projections with those given in Ref. 5 (i.e., $\mathrm{P}_{\mathrm{B}}=200 \mathrm{MW}, \mathrm{E}_{\mathrm{B}}=1,000 \mathrm{MeV}$ ). While finer calibration and/or increased fidelity will lead to improved agreement, both in magnitude and distribution (amongst main cost accounts), the agreement between Ref.-5 and the Parametrics Costing Model is considered adequate for purposes of examining other regions of APT design space. The main differences appear in the power requirements and the associated annual charges; the accelerator model used in the Parametrics Costing Model does not constrain the "wall-plug" accelerator efficiency, $\eta_{A}$, and the higher values used leads to the reduced $\mathrm{AC}_{\mathrm{ELC}}$ and TLCC values reported in the Table-IV benchmarking comparison.

For the $\mathrm{P}_{\mathrm{B}}=200-\mathrm{MW}$ case listed in Table IV, optimization to the minimum-CON condition results only in a minor reduction in TLCC. For example, the Parametrics Costing Model prediction given in Table IV corresponds to a neutron-production capacity of YLD $=1,730$ mol/yr. The minimum-CON design for the same YLD value shifts $P_{B}$ from 200 to 208 $\mathrm{MW}, \mathrm{E}_{\mathrm{B}}$ from 1,000 to $908 \mathrm{MeV}$, and TLCC from 5,240 M\$ to 5,136 M\$ (i.e., a $\sim 100$ MS savings over the $T_{\mathrm{LIF}}=40-\mathrm{yr}$ life of the plant). 


\section{B. Example Parametrics}

All results reported in Sec. III.A. correspond to the input parameters listed in Table III. Two sample variations from those inputs are considered: a) resistive versus superconducting CCL; and b) cost of electricity versus plant availability (e.g.,." "loadcurve") variation.

\section{Resistive versus Superconducting CCL}

Typically, the RF $\rightarrow$ beam conversion occurs with an efficiency $\eta_{B} \sim 0.8$; use of a superconducting cavity surface will eliminated this loss, resulting in a reduction in RF power capital and operating expenditure associated with electrical utilities. Additionally, higher real-estate gradients may be possible with a superconducting CCL, thereby shortening the acceleration structure and reducing its capital cost and the civil engineering costs associated with the accelerator tunnel. The unit cost of the CCL, however, may increase and to some extend counteract the former capital cost reductions. Furthermore, use of a superconducting CCL has implications of both availability (e.g., MTTF versus MTTR) and risk versus contingency that cannot be resolved in the context of the Parametrics Costing Model. Other (presently) unquantifiable elements in the choice between resistive and superconducting CCLs are reduced beam scrape off (larger apertures can be used in superconducting designs) and the relative costs of cooling a copper versus a superconducting structure.

The impact on cost (CON and TLCC) and operating point $\left(E_{B}\right.$ and $\left.P_{B}\right)$ of doubling the realestate gradient and increasing the $\mathrm{CCL}$ unit cost by $50 \%$ is shown on Fig. 13 for the case of minimum CON; the shunt resistance is increased by a factor of $10^{6}$ to mockup the $\mathrm{Cu} \rightarrow$ $\mathrm{SC}$ transition. The Total Life-Cycle Cost and the Cost of Neutrons are seen to decrease by $\sim 18 \%$. Since low accelerator currents no longer translate into decreased $\eta_{B}$ and increased power consumption, the economic incentive to decrease the capital cost of the accelerator structure by increasing $E_{B}$ and decreasing the CCL length is evident from Fig. 13.

\section{Load Curve: Cost of Electricity versus Plant Availability}

To investigate the trade off between plant availability, $\mathrm{p}_{\mathrm{f}}$, and the cost of electricity, $\mathrm{COE}(\mathrm{mil} / \mathrm{kWh})$, for a fixed annual neutron-production capacity, $\mathrm{YLD}^{\prime}=\mathrm{p}_{\mathrm{f}} \mathrm{YLD}=1,300$ $\mathrm{mol} / \mathrm{yr}$, the following "load curve" was assumed:

$$
\operatorname{COE}(\mathrm{mil} / \mathrm{kWh})=10.0+75.3 \mathrm{p}_{\mathrm{f}}
$$

This load curve retrieves the Ref-5 COE $=66.5 \mathrm{mil} / \mathrm{kWh}$ when $\mathrm{p}_{\mathrm{f}}=0.75$. This exercise examines the trade between annual charges for electrical power, $\mathrm{AC}_{\mathrm{ELC}}(\mathrm{M} \$ / \mathrm{yr})$, and the capital cost of increased peak ("name-plate") capacity, $\mathrm{YLD}\left(\mathrm{mol} / \mathrm{yr}\right.$ ) or $\mathrm{P}_{\mathrm{B}}(\mathrm{MW})$, needed to meet the annual neutron-production goal of $\mathrm{YLD}^{\prime}$ (mole/yr).

The dependence of TLCC $(M \$), C O N(M \$ / m o l), P_{B}(M W)$, and $E_{B}(M e V)$, along with the load curve, on plant availability is shown on Fig. 14 for minimum-CON conditions. While higher-capacity systems constrained to the Eqn. (18) load curve favor reduced beam energy to achieve minimum-CON conditions, the dependence of TLCC and CON on $\mathrm{p}_{f}$ is relatively weak, indicating a shallow optimum in the range $p_{f}=0.70-0.80$ for the load 
curve assumed; under these condition, the choice is ambivalent as to whether the APT cash flow is directed towards payments to the servicing utility or to servicing the capital debt.

\section{CONCLUSIONS}

Using relatively few parameters and judiciously choosing calibration points, a Parametric Costing Model in a preliminary (rudimentary) form has been created both to benchmark the detailed costing of the preconceptual APT design ${ }^{5}$ and to extend vis a vis a two-parameter search in $E_{B}-P_{B}(Y L D)$ "space" an understanding of important cost sensitivities. The main goal of this study is to illustrate the versatility of this approach to cost-based design and to suggest a tool for further development and use in future APT engineering designs. For this application to come to fruition, however, the physics, engineering, and costing models reported herein must be enhanced considerably both in intrinsic detail and in connectivity between key disciplines and related subsystems. Areas where model enhancement or development is needed can be identified with the need to resolve on a cost base the following key issues:

- Superconducting versus Copper CCL: operational and cost trade offs related to reduced capital costs related to reductions in RF-power systems and reduced length of accelerator structure (high "real-estate" gradients); differences in unit costs, $\mathrm{UC}_{\mathrm{CCL}}(\mathrm{M} \$ / \mathrm{m})$, for superconducting versus copper CCLs; increased "wall-plug" efficiency and differences in coolant power requirements, and impact on annual operating charges; differences in overall plant reliability, RAMI issues, and MTTR versus MTTR.

- Pulse versus Steady-State Beam: cost and efficiency of added energy store versus increased RF $\rightarrow$ beam efficiency and increased (if any) "wall- plug" efficiency as the beam duty factor, $f_{D}$, is decrease below 1.0; relationship of this trade off with overall APT capacity, as measured by beam power, $P_{B}$.

- Target/Blanket Multiplicity: trade offs related to APT capacity as measured by: $P_{B}$, Target power density; $\mathrm{p} \rightarrow \mathrm{n}$ and $\mathrm{n} \rightarrow{ }^{3} \mathrm{H}$ conversion efficiency; Target replacement frequency and issues of RAMI, waste generation, and replacement costs; added costs and operational complexity associated with the High-Energy Beam Transport/Splitting systems.

- Accelerator Multiplicity: superconducting versus resistive CCL; scalability of and margins for tritium-production capacity; overall plant production reliability.

- Cost/Performance versus Accelerator and Target/Blanket Connectivity: cost/performance tradeoffs with Target/Blanket configuration and interrelationships between $\mathrm{Y}(\mathrm{n} / \mathrm{p}), \mathrm{TPN}(\mathrm{t} / \mathrm{n}), \mathrm{TPP}=\mathrm{Y} \times[\mathrm{TPN}]$, target surface and volumetric power density, proton-beam energy, (added) neutron shield, (added) activation, radiation lifetime, (added) waste stream, etc. 


\section{REFERENCES}

1 "Accelerator Topical Report, " Los Alamos National Laboratory Accelerator Production of Tritium Project, Los Alamos National Laboratory report LA-12668-MS (September 1993).

2. “Target/Blanket Topical Report, " Los Alamos National Laboratory Accelerator Production of Tritium Project, Los Alamos National Laboratory report LA-12670-MS (September 1993).

3. "Tritium Extraction Facility Technical Report, "Los Alamos National Laboratory Accelerator Production of Tritium Project, Los Alamos National Laboratory document LA-UR-93-3113 (September 1993).

4. "Balance-of-Plant Topical Report, " Los Alamos National Laboratory Accelerator Production of Tritium Project, Los Alamos National Laboratory report LA-12665-MS (September 1993).

5. "APT Cost and Schedule Report-Preconceptual Design," Los Alamos National Laboratory Laboratory Production of Tritium Project, Los Alamos National Laboratory document LA-CP-94-28 (March 1994).

6. "Technical Reference Book for the Energy Economic Data Base Program EEDB Phase IX (1987)," United States Department of Energy report DOE/NE-0092 (September 1988).

7. NUS Corporation, "Guide for the Economic Evaluation of Nuclear Reactor Plant Designs," NUS Corporation report NUS-531 (January 1963).

8. R. A. Krakowski, "ATW Economics," Nucl. Technol. (to be published, 1995); also, Los Alamos National Laboratory document LA-UR-93-2231 (August 22, 1994).

9. C. A. Beard, J. J. Buksa, M. W. Cappiello, J. W. Wiley, J. S. Elson, J. R. Ireland, R. A. Krakowski, B. J. Krohn, W. C. Sailor, and J. L. Sapir, "Neutronics and Engineering Design of the Aqueous-Slurry ATW Blanket," Nucl. Technol., (to be published, 1995); also, Los Alamos National Laboratory document LA-UR-941673(Rev.) (January 1995).

10. "Nuclear Energy Cost Data Base - A Reference Data Base for Nuclear and Coal-Fired Power Plant Generation Cost Analysis," United States Department of Energy report DOE/NE-0095 (September 1988).

11. J. G. Delene and C. R. Hudson II, "Cost Estimate Guidelines for Advanced Nuclear Power Technologies," Oak Ridge National Laboratory report ORNL/TM-10071/R3 (March 1993).

12. R. A. Krakowski, "Analytic Cost-Bassed Scaling of Current and Energy for Accelerator-Production of Neutrons," personal communication, Los Alamos National Laboratory memo A-3:92-136(U) (May 18, 1992). 
13. R. A. Krakowski, "Scaling and Cost Tradeoffs for ATW: Preliminary Considerations," Specialists' Meeting on Accelerator-Based Transmutation, Paul Scherrer Institute Wuerenlingen/Villigen, Switzerland (March 24-26, 1992); also, Los Alamos National Laboratory document LA-UR-92-530(Rev.) (March 1, 1992).

14. R. A. Krakowski, "Preliminary Cost-Based Optimization of Power Density and (Target-Blanket) Modularity for ADEP," ADEP Systems Studies Accomplishments for FY1994, Los Alamos National Laboratory document LA-UR-94-3594 (October $20,1994)$.

15. G. Russell, "Interim Results: ATW Pv Bare-Target Neutronics," personal communication, Los Alamos National Laboratory (March 1, 1991).

16. G. P. Lawrence, "The Los Alamos Accelerator Transmutation of Nuclear Waste (ATW) Concept," Los Alamos National Laboratory document ATW-9 (April 15, 1992).

17. R. L. Miller, W. R. Spears, R. Hancox, and R. A. Krakowski, "Comparison of EURATOM and U.S. Estimated of Fusion Reactor Costs," Fus. Technol., 19(3,2A), 813 (1991).

18. "The Economics of the Nuclear Fuel Cycle," Nuclear Energy Agency, OECD (1985). 


\section{NOMENCLATURE}

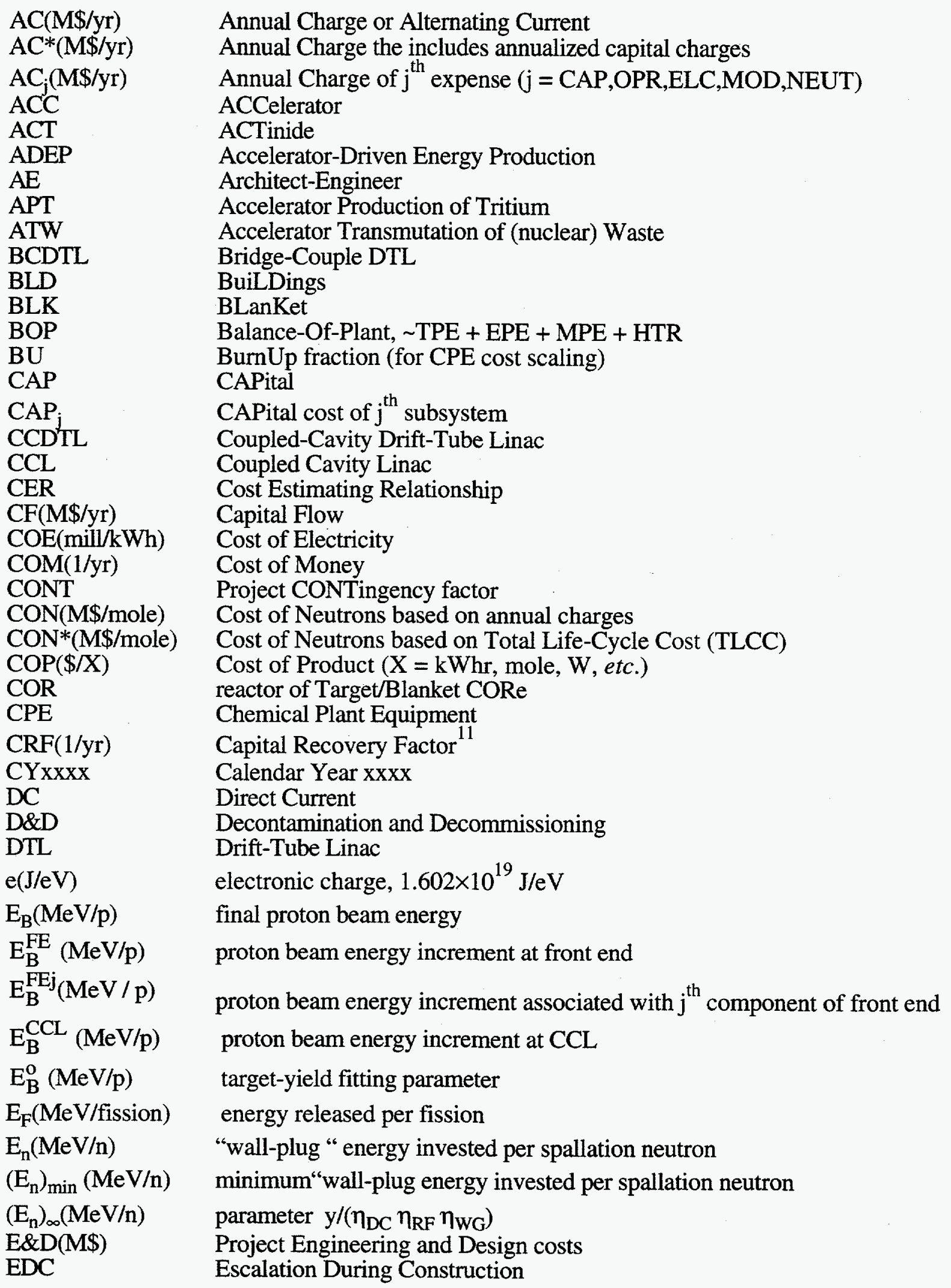




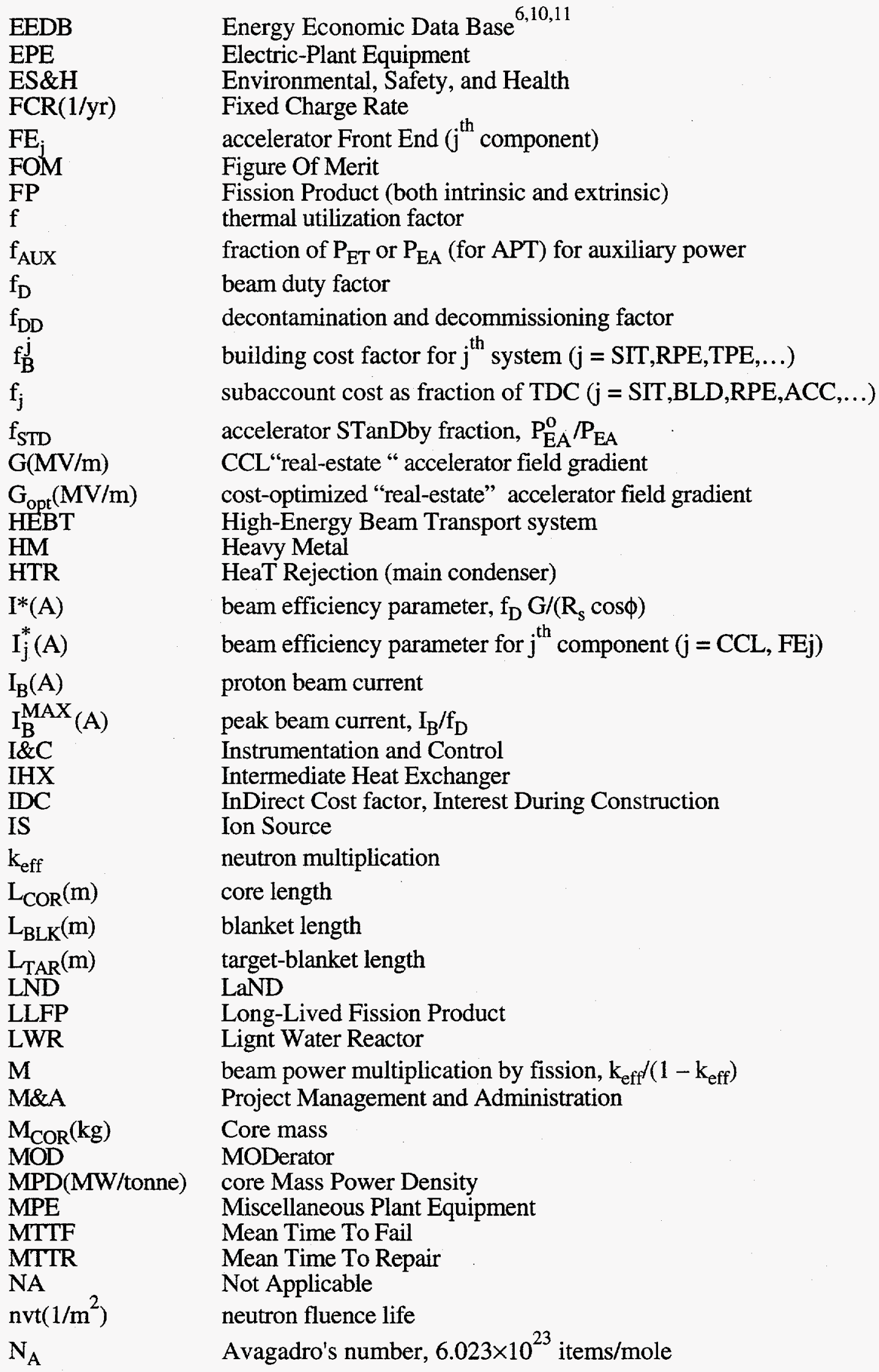




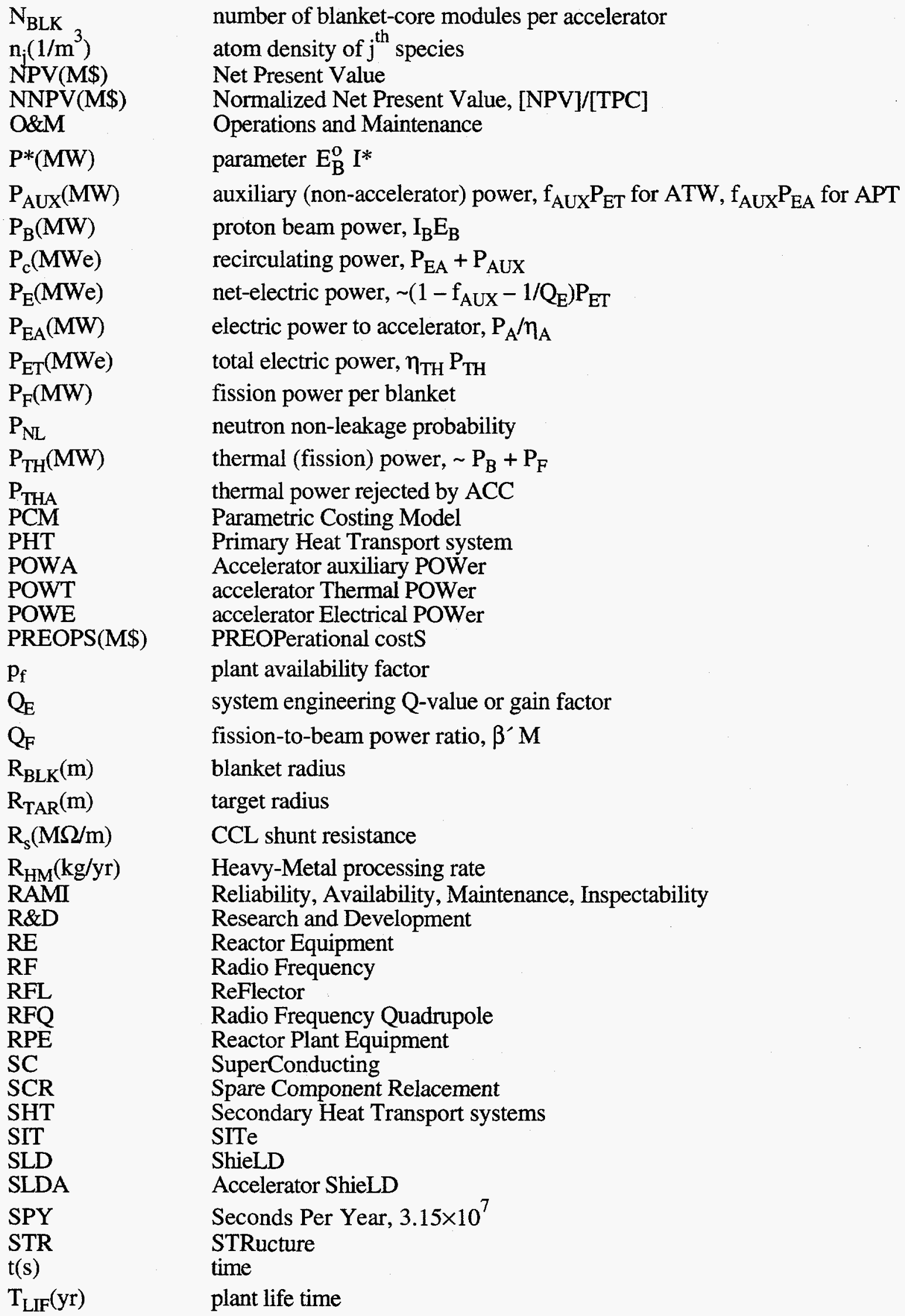




\begin{tabular}{|c|c|}
\hline $\begin{array}{l}\text { T/B } \\
\text { TAR } \\
\text { TARM } \\
\text { TART } \\
\text { TC(M\$) } \\
\text { TDC(M\$) } \\
\text { TEC(M\$) } \\
\text { TLCC(M) } \\
\text { TPE } \\
\text { TPC(M\$) } \\
\text { TPN(t/n) }\end{array}$ & $\begin{array}{l}\text { Target/Blanket } \\
\text { TARget } \\
\text { TARget Mechanical } \\
\text { TARget Thermal } \\
\text { Total Cost } \\
\text { Total Direct Cost } \\
\text { Total Estimated Cost (TPC plus PREOPS and D\&D) } \\
\text { Total Life-Cycle Cost } \\
\text { Turbine Plant Equipment } \\
\text { Total Project Cost (TC plus M\&A, E\&D, and Project Contingency costs) } \\
\text { tritons produced per target neutron generated }\end{array}$ \\
\hline $\begin{array}{l}\text { TPP(t/p) } \\
\text { TUN }\end{array}$ & $\begin{array}{l}\text { tritons produced per proton, } \sim \mathrm{Y} \times[\mathrm{TPN}] \\
\text { TUNnel }\end{array}$ \\
\hline $\mathrm{UC}_{\mathrm{j}}(\$ / \mathrm{X})$ & Unit Cost $\left(\mathrm{X} \rightarrow \mathrm{kg}, \mathrm{We}, \mathrm{Wt}, \mathrm{m}^{3}\right.$, etc. $)$ \\
\hline $\begin{array}{l}\mathrm{V}_{\mathrm{BLK}}\left(\mathrm{m}^{3}\right) \\
\mathrm{VSL} \\
\mathrm{WIN} \\
\mathrm{y}(\mathrm{MeV} / \mathrm{n}) \\
\mathrm{Y}(\mathrm{n} / \mathrm{p})\end{array}$ & $\begin{array}{l}\text { blanket volume } \\
\text { reactor VeSseL } \\
\text { WINdow } \\
\text { target-yield fitting parameter } \\
\text { target neutron yield }\end{array}$ \\
\hline $\begin{array}{l}\mathrm{YLD}(\mathrm{mole} / \mathrm{yr}) \\
\alpha\end{array}$ & $\begin{array}{l}\text { target neutron production rate, }\left(\mathrm{I}_{\mathrm{B}} \mathrm{Y}\right) \mathrm{SPY} /\left(\mathrm{e} \mathrm{N}_{\mathrm{A}}\right)=\beta\left(\mathrm{Y} / \mathrm{E}_{\mathrm{B}}\right) \mathrm{P}_{\mathrm{B}} \\
{ }^{233} \mathrm{U} \text { capture-to-fission ratio }\end{array}$ \\
\hline$\beta$ & parameter $[\mathrm{SPY}] / \mathrm{e} / \mathrm{N}_{\mathrm{A}}$ \\
\hline$\beta^{\prime}$ & $\begin{array}{l}\text { normalized fission-to-beam } \\
(\mathrm{MeV}(\mathrm{mol} / \mathrm{yr}) / \mathrm{MW}\end{array}$ \\
\hline$\delta_{\mathrm{w}}(\mathrm{m})$ & reactor vessel wall thickness \\
\hline$\varepsilon$ & recirculating power fraction, $1 / \mathrm{Q}_{\mathrm{E}}$ \\
\hline$\eta$ & fission neutrons per fuel absorption, $v /(1+\alpha)$ \\
\hline$\eta_{\mathrm{A}}$ & accelerator"wall-plug " efficiency \\
\hline$\eta_{\mathrm{B}}^{\mathrm{j}}$ & $R F \rightarrow$ beam efficiency for $j^{\text {th }}$ component $(j=F E, C C L)$ \\
\hline$\eta_{D C}$ & $\mathrm{AC} \rightarrow \mathrm{DC}$ conversion efficiency \\
\hline$\eta_{\mathrm{TH}}$ & thermal-to-electric conversion efficiency \\
\hline$\eta_{\mathrm{RF}}$ & $\mathrm{DC} \rightarrow \mathrm{RF}$ conversion efficiency \\
\hline$\eta_{\mathrm{WG}}$ & RF waveguide efficiency \\
\hline$\eta_{\mathrm{WP}}$ & "Wall-Plug " efficiency, $\eta_{\mathrm{DC}} \eta_{\mathrm{RF}} \eta_{\mathrm{WG}}$ \\
\hline$\phi($ degree $)$ & phase angle between beam packet and RF \\
\hline$<\phi>\left(1 / \mathrm{m}^{2} \mathrm{~s}\right)$ & blanket-volume-averaged (one-group, total) neutron flux \\
\hline$\phi\left(1 / \mathrm{m}^{2} \mathrm{~s}\right)$ & peak flux in blanket \\
\hline$\rho_{\mathrm{j}}\left(\mathrm{kg} / \mathrm{m}^{3}\right)$ & mass density of $j^{\text {th }}$ species \\
\hline & microscopic absorption cross section for $j^{\text {th }}$ species \\
\hline$\Sigma_{j}(1 / \mathrm{m})$ & macroscopic absorption cross section for $j^{\text {th }}$ species \\
\hline$\tau_{j}(s)$ & $\begin{array}{l}\text { chemical-processing (removal) time or inverse removal rate for } j^{\text {th }} \\
\text { species }\end{array}$ \\
\hline
\end{tabular}


Table I. Top-Level EEDB Program Code of Accounts ${ }^{11}$ and Modifications Made ${ }^{5}$ to Adapt to APT

Account

Number

Account Description ${ }^{(a)}$

Fraction of TDC

or Indicated

Number

20

21

22

23

24

25

26

27

Land and Land Rights ${ }^{(b)}$

Structures and Improvements ${ }^{\text {(b) }}$

Ratio $^{(n)}$

Reactor Plant Equipment ${ }^{(\mathrm{c})}$

Turbine Plant Equipment ${ }^{(\mathrm{d}, \mathrm{e})}$

Electric Plant Equipment ${ }^{(\mathrm{e})}$

Miscellaneous Plant Equipment ${ }^{(\mathrm{e})}$

0.0

Main Condenser Heat Rejection System ${ }^{(\mathrm{e}, \mathrm{f})}$

Accelerator Equipment ${ }^{(\mathrm{g})}$

Total Direct Costs, TDC ${ }^{(a)}$

0.163

$0.102^{(0)}$

0.0

$0.058^{(\mathrm{p})}$

$0.041^{\text {(p) }}$

$0.021^{(\mathrm{p})}$

$0.554^{(\mathrm{q})}$

$0.975^{(\mathrm{r})}$

Construction Services $^{(h)}$

Architect-Engineer Home Office Engineering and Service ${ }^{(\mathrm{h})}$

Field Office Supervision and Service ${ }^{(\mathrm{h})}$

Owners' Expenses ${ }^{(\mathrm{h}, \mathrm{i})}$

Reactor Manufactures' Home Office Engineering and Services(h,i)

Total Indirect Costs, $\mathrm{IDC}_{1}^{(\mathrm{h}, \mathrm{n})}$

$\mathrm{IDC}_{1} / \mathrm{TDC}=0.35$

$[\text { Total Cost, } \mathrm{TC}]^{(\mathrm{j})}$

$\mathrm{TC} / \mathrm{TDC}=1.35$

[Total Estimated Cost, TEC $]^{(\mathrm{k})}$

$$
\mathrm{TEC} / \mathrm{TC}=1.79-1.92^{(\mathrm{s})}
$$

Total Project Cost, TPC ${ }^{(1)}$

TPC/TC $=1.79-1.92^{(t)}$
TPC/TC $=1.16-1.15^{(t)}$

4

491

492

493
Chemical Plant Equipment ${ }^{(\mathrm{m})}$
Construction Services $^{(h)}$
AE Home Office Engineering and Service ${ }^{(h)}$
Field Office Supervision and Service ${ }^{(h)}$

(a) Each account is comprised of three main components: (Factory) Equipment; Installation (Site Labor); (Site) Materials.

(b) Land and Site costs are usually not significant and are combined here with Structures and Improvements, which in Ref. 5 includes the Accelerator Tunnel, High-Energy-Beam Transport Tunnel, Klystron Gallery, Front-End Structures, etc; structures and tunnels associated with the Accelerator Equipment contribute 59.1\% of Account 21. 
Primarily the Target/Blanket and the Primary Heat-Transport Systems of the APT applications.

(d) Not required for the present (sub-goal) APT application.

(e) Together, form the Balance of Plant.

(f) While a large system for a $>1,000$-GWe power generation station, this subsystem for the APT application will deal with $\sim 1 / 6$ the power under less demanding thermal-hydraulic conditions.

(g) For the ATW power plant application ${ }^{8,9}$, the Accelerator Equipment was included as a major subaccount under the Reactor Plant Equipment Account 22.; inclusion here under a new Account 27. follows the convention adopted in Ref. 5.

(h) These Accounts together form the main contributions to the Indirect Charges.

(i) No counterpart for the present APT application is yet to be identified.

(j) Sum of above-listed accounts

(k) The Total Estimated Costs are the sum of the Total Direct Costs and the Total Indirect Costs with Management and Administrative Costs and Project Contingency Costs (above and beyond "local" Contingency Costs added to particular subsystem components and include as part of the respective Direct Cost); the Total Estimated Cost, as reported here, is not identified directly in the EEDP Program Code of Accounts.

(1) The addition of Preoperational Costs (including startup costs) and Decontamination and Decommissioning Costs to the Total Estimated Cost gives the Total Project Cost.

(m) The Chemical Plant Equipment Account, as applied to the net-power-producing ATW ${ }^{8,9}$, included fission-product, actinide, and (target) spallation-product processing; this major subsystem for the ATW application was allocated to Account 27. For the APT application, a separate Account 4. was defined, ${ }^{5}$ which also carriesd separate Indirect Cost subaccounts, as is indicated.

(n) Based on the APT ${ }^{3} \mathrm{He}$-Target/Blanket design reported in Ref. 5; the cost of the Tritium Extraction Facility is included in TDC.

(o) The Target/Blanket comprises $79.8 \%$ of this account, with the remainder beginning the Primary Heat-Transport system.

(p) The total Balance of Plant comprises $12.0 \%$ of the Total Direct Cost.

(q) The RF-power systems comprises $33.2 \%$ of this account; if all buildings and structures associated with the accelerator where added to this account, the Account 27. would contribute $65.0 \%$ to TDC.

(r) The remaining $2.5 \%$ is allocated to (initial) spare components.

(s) The Total Estimated Cost is the sum of TC, Engineering and Design (E\&D), Management and Administration (M\&A), and Contingency (CONT) costs related to the Project as a whole. For the Ref.-5 case, $(\mathrm{E} \& \mathrm{D}+\mathrm{M} \& \mathrm{~A}) / \mathrm{TC}=\mathrm{IND}_{2} / \mathrm{TC}=0.30$, and CONT/TC for confidences in the range $50-75 \%$ is in the range $0.49-0.62$; the range given for TEC/TC reflects the confidence range reported in Ref. 5.

(t) The Total Project Cost is taken as the sum of TEC, Preoperational (PREOP), and the (up-front) Decontamination and Decommissioning (D\&D) costs. For the ${ }^{3} \mathrm{He}-$ Target/Blanket APT case reported in Ref. 5: PREOPS/TDC $=0.38 ;$ PREOPS/TC $=0.28$; $\mathrm{D} \& \mathrm{D} / \mathrm{TDC}=0.15 ;$ and $\mathrm{D} \& \mathrm{D} / \mathrm{TC}=0.11$. 
Table II. Accelerator Parameters ${ }^{16}$ Used in ATWSC $^{8}$

parameter

Accelerator component (Fig.4)

Subscript/superscript notation, $\mathbf{j}$

Added beam energy, $\left.E_{B} j\right)(M e V)$

$R F$ coupling efficiency, $\eta_{B}^{j}\left(I_{B}=0.25 A\right)^{(a)}$

Coupling parameter, $\mathrm{I}_{\mathrm{j}}^{*(\mathrm{~b})}(\mathrm{A})$

- Ref. 16

- This model ${ }^{(a)}$

\begin{tabular}{ccc}
\multicolumn{3}{c}{ value } \\
RFQ +DTL & BCDTL & $\begin{array}{l}\text { CCL } \\
\text { CCL }\end{array}$ \\
FE1 & FE2 & $1,520$. \\
$0.5+17.5=20$. & 60. & 0.8526 \\
& & \\
0.5952 & 0.7143 & \\
& & $0.4322^{(\mathrm{b})}$ \\
0.0085 & 0.1021 & $0.3282^{(\mathrm{c})}$
\end{tabular}

(a) $\eta_{B}^{j}=1 /\left(1+I_{j}^{*} / I_{B}\right) ; I_{j}^{*}=G /\left(R_{s} \cos \phi\right)$

(b) for $\mathrm{G}=1 \mathrm{MV} / \mathrm{m}$ and $\cos \phi=0.866, \mathrm{R}_{\mathrm{s}}=26.7 \mathrm{M} \Omega / \mathrm{m}$

(c) this case pertains to $R_{S}$ being a function of CCL beam energy, $E_{B}^{C C L}$, which for $\mathrm{R}_{\mathrm{s}}(\mathrm{M} \Omega / \mathrm{m})=36.70-2400.0 / \mathrm{E}_{\mathrm{B}}^{\mathrm{CCL}}$ corresponds to $\mathrm{R}_{\mathrm{s}}=35.1 \mathrm{M} \Omega / \mathrm{m}$ for $\mathrm{E}_{\mathrm{B}}^{\mathrm{CCL}}=1,520$ $\mathrm{MeV} / \mathrm{p}\left(\mathrm{E}_{\mathrm{B}}=1,600 \mathrm{MeV} / \mathrm{p}\right)$. 
Table III. Summary of Key Inputs to APT Parametric Costing Model

Parameter

Value

\section{Direct Costing Parameters}

Land $\mathrm{UC}_{\mathrm{LND}}(\mathrm{M} \$$ /hecter $)$

$0.00^{(\mathrm{a})}$

Site improvement factor (of building direct cost), $\mathrm{f}_{\mathrm{B}}^{\mathrm{SIT}}$

0.02

Accelerator Equipment building factor (of ACC direct cost), $\mathrm{f}_{\mathrm{B}}^{\mathrm{ACC}}$

$0.00^{(\mathrm{b})}$

Accelerator tunnel and buildings, $\mathrm{UC}_{\mathrm{TUN}}(\mathrm{M} \$ / \mathrm{m})$

0.10

Target/Blanket building factor (of RPE direct cost), $\mathrm{f}_{\mathrm{B}}^{\mathrm{RPE}}$

0.50

Turbine Plant Equipment building factor (of TPE direct cost), $\mathrm{f}_{\mathrm{B}}^{\mathrm{TPE}} \quad 0.10$

Balance of Plant building factor (of BOP direct cost), $\mathrm{f}_{\mathrm{B}}^{\mathrm{BOP}(\mathrm{c})} \quad 0.03$

Chemical Plant Equipment building factor (of CPE direct cost), $\mathrm{f}_{\mathrm{B}}^{\mathrm{CPE}} \quad 0.05$

Accelerator thermal-power rejection, $\mathrm{UC}_{\mathrm{ACC}}^{\mathrm{PHT}}(\$ / \mathrm{Wt})^{(\mathrm{d})} \quad 0.05$

Accelerator electrical distribution, $\mathrm{UC}_{\mathrm{ACC}}^{\mathrm{EPE}}(\$ / \mathrm{We})^{(\mathrm{d})} \quad 0.10$

Accelerator structure, $\mathrm{UC}_{\mathrm{CCL}}(\mathrm{M} \$ / \mathrm{m})^{(\mathrm{e}, \mathrm{f})}$

$\mathrm{RF}$ power, $\mathrm{UC}_{\mathrm{RF}}(\mathrm{S} / \mathrm{W})$

Target/Blanket, $\mathrm{UC}_{\mathrm{TB}}[\$ / \mathrm{W}(\text { beam })]^{(\mathrm{f})} \quad 0.45$

Primary Heat Transport, $\mathrm{UC}_{\mathrm{PHT}}(\$ / \mathrm{Wt})^{(\mathrm{f})} \quad 0.11$

Turbine Plant Equipment, $\mathrm{UC}_{\mathrm{TPE}}(\$ / \mathrm{We})$

Electric Plant Equipment, $\mathrm{UC}_{\mathrm{EPE}}(\$ / \mathrm{We}) \quad 0.12$

Miscellaneous Plant Equipment, $\mathrm{UC}_{\mathrm{MPE}}(\$ / \mathrm{We}) \quad 0.08$

Heat Rejection Equipment, $\mathrm{UC}_{\mathrm{HTR}}(\$ / \mathrm{Wt}) \quad 0.04$

Chemical Plant Equipment, $\mathrm{UC}_{\mathrm{CPE}}(\$ / \mathrm{kg} / \mathrm{yr})^{(\mathrm{g})} \quad 0.00$

Tritium Extraction Facility, $\mathrm{UC}_{\mathrm{TEF}}[\$ / \mathrm{W}(\text { beam })]^{(\mathrm{g})} \quad 0.20$

Initial Spare Component Replacement factor (of TDC), $\mathrm{f}_{\mathrm{SCR}} \quad 0.025$

\section{Indirect Costing Parameters}

Indirect cost factor for TDC $\rightarrow \mathrm{TC}, \mathrm{IDC}_{1}$

Indirect cost factor for TC $\rightarrow$ TEC, $\mathrm{IDC}_{2} \quad 0.30$

Contingency factor for TC $\rightarrow$ TEC, CONT ${ }^{(\text {h) }} \quad 0.50$

Preoperation cost factor (of TC), PREOPS $\quad 0.28$

Decommissioning and Decontamination cost factor (of TC) ${ }^{(\mathrm{i})} \quad 0.11$ 
Table III. Summary of Key Inputs to APT Parametric Costing Model (Cont-1)

Parameter

Value

Annual Charge and Other Financial Factors

Market Cost of Electricity, $\mathrm{COE}(\mathrm{mil} / \mathrm{kWh})$

66.50

Annual operating charge factor (of TC), $\mathrm{f}_{\mathrm{OP}}(1 / \mathrm{yr})$

0.06

Operations cost of money, $\mathrm{COM}_{\mathrm{OPR}}(1 / \mathrm{yr})$

0.04

Construction cost of money, $\mathrm{COM}_{\mathrm{CON}}(1 / \mathrm{yr})$

0.04

Key Calandar Year dates

- Reference year, $\mathrm{CY}_{\mathrm{REF}}$

1993.

- Start payments, $\mathrm{CY}_{\mathrm{SRT}}$

1996.

- Peak payments, $C Y_{\mathrm{PEK}}$

2004.

- Start operations, $\mathrm{CY}_{\mathrm{OPR}}$ 2008.

Plant (economic) life time, $\mathrm{T}_{\mathrm{LIF}}(\mathrm{yr})$

40.

Capital Recovery Factors, CRF(T,COM)(1/yr)

- $\mathrm{CRF}\left(\mathrm{CY}_{\mathrm{OPR}}-\mathrm{CY}_{\mathrm{REF}}+\mathrm{T}_{\mathrm{LIF}}, \mathrm{COM}_{\mathrm{OPR}}\right)$

0.0452

- $\mathrm{CRF}\left(\mathrm{CY}_{\mathrm{OPR}}-\mathrm{CY}_{\mathrm{REF}}, \mathrm{COM}_{\mathrm{OPR}}\right)$

- $<\mathrm{CRF}>$

0.0899

0.0910

0.5847

0.0532

Effective Fixed Charge Rate, FCR $(1 / \mathrm{yr})=[\mathrm{NNPV}] \times<\mathrm{CRF}>(1 / \mathrm{yr})$

0.02

Initial normalized Cash Flow, $\lambda_{\mathrm{I}}(1 / \mathrm{yr})=\mathrm{CF}_{\mathrm{I}} / \mathrm{TPC}^{(\mathrm{j})}$

0.1655

\section{Accelerator Parameters}

Front-end beam energy, $\mathrm{E}_{\mathrm{B}}^{\mathrm{FE}}(\mathrm{MeV})$

Real-estate gradient, G(MV/m)

80.

Cosine of RF/bunch phase angle, $\cos \phi$

1.0

Beam duty factor, $f_{D}$

0.866

$\mathrm{RF} \rightarrow$ beam efficiency factor, $I^{*}(\mathrm{~A})$

1.0

0.033

\section{Target/Blanket Parameters}

Target neutron-yield parameters $\left[Y(n / p)=\left(E_{B}-E_{B}^{o}\right) / y\right]$

- inverse slope, $\mathrm{y}(\mathrm{MeV} / \mathrm{n})$

- intercept, $\mathrm{E}_{\mathrm{B}}^{\mathrm{o}}(\mathrm{MeV} / \mathrm{p})$ 201.4

Blanket neutron multiplication, $\mathrm{k}_{\mathrm{eff}} \quad 0.0$

Fission neutrons per fission, $v \quad 2.90$

Nominal target radius, $\mathrm{R}_{\mathrm{TAR}}(\mathrm{m}) \quad 0.56$

Nominal target length, $\mathrm{L}_{\mathrm{TAR}}(\mathrm{m}) \quad 2.0$

Peak-to-average ratio of neutron flux, $\phi /\langle\phi\rangle \quad 2.0$

Radiation life, $\mathrm{nvt}=\phi \tau\left(10^{26} / \mathrm{m}^{2}\right) \quad 2.0$ 
Table III. Summary of Key Inputs to APT Parametric Costing Model (Cont-2)

Parameter

Value

\section{Plant Parameters}

Thermal-to-electric conversion efficiency, $\eta_{\mathrm{TH}} \quad 0.0$

$\mathrm{AC} \rightarrow \mathrm{DC}$ conversion efficiency, $\eta_{\mathrm{DC}} \quad 0.86$

$\mathrm{DC} \rightarrow \mathrm{RF}$ conversion efficiency, $\eta_{\mathrm{RF}}$

RF wave-guide efficiency, $\eta_{W G} \quad 0.98$

"Wall-plug " $\rightarrow$ cavity efficiency, $\eta_{\mathrm{WP}}=\eta_{\mathrm{DC}} \eta_{\mathrm{RF}} \eta_{\mathrm{WG}}$

Auxiliary power fraction, $\mathrm{f}_{\mathrm{AUX}}=\mathrm{P}_{\mathrm{AUX}} / \mathrm{P}_{\mathrm{EA}}$

Accelerator stand-by fraction, $\mathrm{f}_{\mathrm{STD}}=\mathrm{P}_{\mathrm{EA}}^{\mathrm{o}} / \mathrm{P}_{\mathrm{EA}}$

Plant availability factor, $\mathrm{p}_{\mathrm{f}} \quad 0.75$

(a) A nominal 10-M\$ charge is added to this account.

(b) Included in the following unit cost.

(c) Balance of Plant is defined here as Turbine Plant Equipment (none for this APT), Electric Plant Equipment, Miscellaneous Plant Equipment, and Heat Rejection Equipment.

(d) Local (i.e., not BOP) to the Accelerator Equipment Account 27.

(e) Covers all components of the accelerating structure: Ion Source, Radio-Frequency Quadrupole, Drift-Tube Linac, Bridge-Coupled Drift-Tube Linac, Coupled-Cavity Linac, and High-Energy Beam Transport systems (Fig. 4).

(f) Both Accelerator Equipment and Target/Blanket systems require greater engineering resolution in this parametric costing model. The Target/Blanket and Primary Heat Transport Systems comprise most of the Reactor Plant Equipment Account 22; studies of ATW systems 8 , however, included the Accelerator Equipment as a major subaccount in Account 22.

(g) Chemical Plant Equipment as used here designates those systems that deal with spallation and fission products; in a broader context, both these and the Tritium Extraction Facility defined for APT should be co-located under the Chemical Plant Equipment account, and brought into the 200-series of accounts (e.g., Account 28.)

(h) A Project-wide contingency factor of magnitude dependent on the level desired confidence in achieving the projected $\mathrm{TEC}^{5}$; local or subsystem contingency factors are assume to be included in the respective CERs.

(i) Decommissioning and Decontamination charges actually should be time-multiplied in an escrow account that assures the required funds are available when needed.

(j) Refer to Fig. 3 ; $\lambda_{\max }$ is determined from constraint that the area under the $\mathrm{Cf}_{\mathrm{j}}$ curve is unity. 
Table IV. Comparison Between Parametric Costing Model and Cost Estimate of APT Preconceptual Design ${ }^{5}$

Acount

Number

$$
\text { Account Description }^{(a)}
$$

20 Land and Land Rights

21 Structures and Improvements

22 Reactor Plant Equipment

23 Turbine Plant Equipment

24 Electric Plant Equipment

25 Miscellaneous Plant Equipment

26 Main Heat Rejection System

BOP $(23+24+25+26)$

27 Accelerator Equipment

4 Chemical Plant Equipment

Initial spare components

Total Direct Costs, TDC(M\$)

Total Cost, TC(M\$)

Total Estimated Cost, TEC(M\$)

Preoperational Costs, PREOPS(M\$)

Decon. and Decommissioning, D\&D(M\$)

Total Project Cost, TPC(M\$) ${ }^{\text {(d) }}$

Annual Charges, AC(M $\$ / y r)$

- electrical power

- other

Total Life-Cycle Cost, TLCC(M\$)

$\begin{array}{ll}\text { Ref. } 5^{(\mathrm{b})} & \text { Parametric } \\ & \text { Costing Model }\end{array}$

$\begin{array}{ll}0.0 & 0.0 \\ 0.163 & 0.176 \\ 0.102 & 0.102 \\ 0.0 & 0.0 \\ 0.058 & 0.049 \\ 0.041 & 0.031 \\ 0.021 & 0.011 \\ 0.120 & 0.091 \\ 0.554 & 0.596 \\ 0.036 & 0.036 \\ 0.025 & 0.000^{(\mathrm{c})}\end{array}$

1,088 .

1,469 .

2,627 .

413.

160.

1,126 .

1,520 .

2,736

426.

167.

3,040 .

3,162 .

346.

$256 .{ }^{(e)}$

90.

5,925 .
300.

$208^{(\mathrm{e})}$

92.

\footnotetext{
(a) Accounts listed as fractions of TDC

(b) ${ }^{3} \mathrm{He}$ target option, contingency for $50 \%$ confidence, $\mathrm{E}_{\mathrm{B}}=1,000 \mathrm{MeV}, \mathrm{P}_{\mathrm{B}}=200 \mathrm{MW}$.

(c) Already included in above fractions.

(d) Does not include D\&D.

(e) Based on $\mathrm{COE}=66.5 \mathrm{mil} / \mathrm{kWh}$; Parametric Costing Model accelerator model gives higher "wall-plug " efficiency and lower accelerator power requirement.
} 


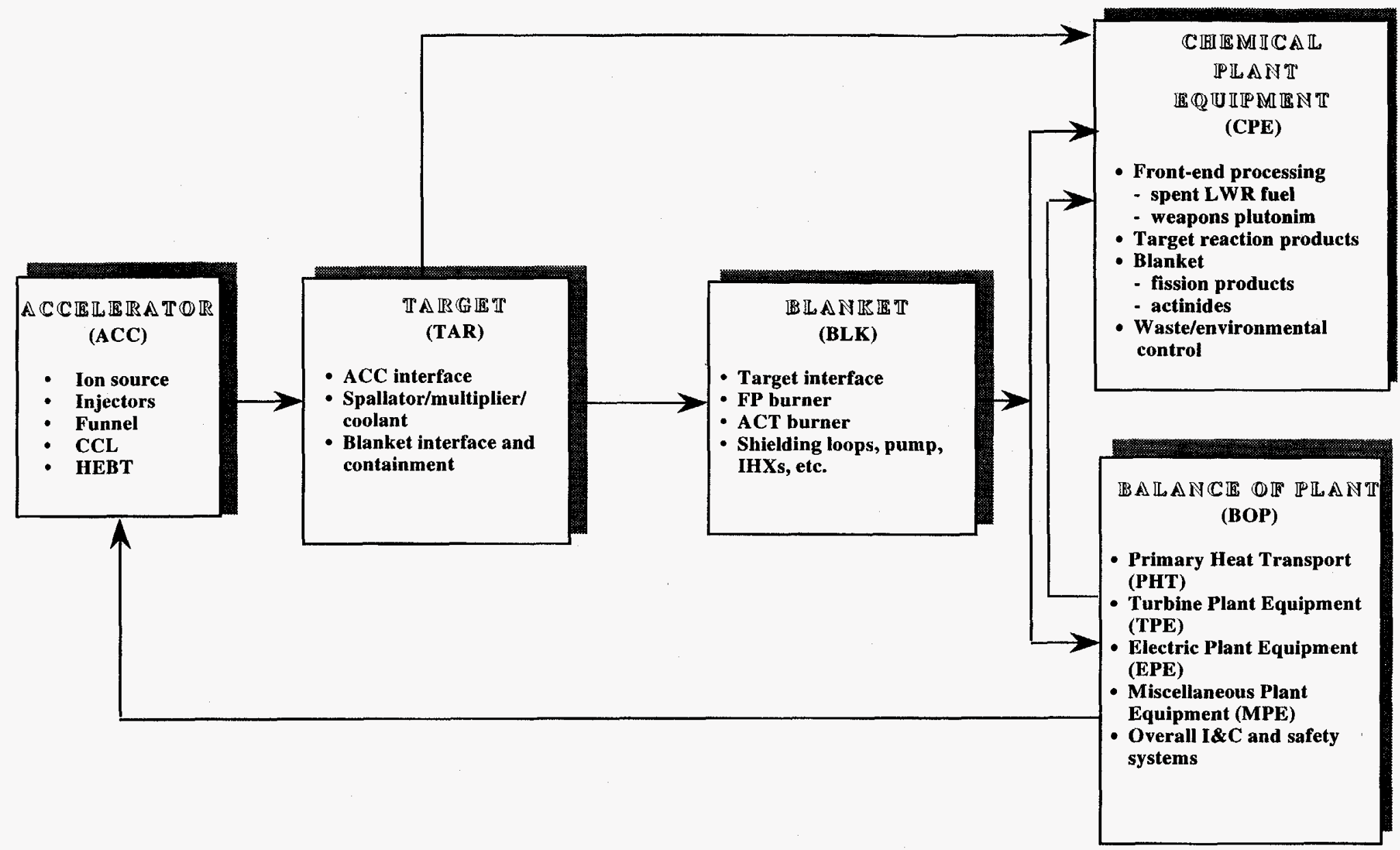

Figure 1. Key subsystems and power flows in an ATW or APT system; in the present APT concept: no conversion of thermal power captured in the Target/Blanket system to electricity is envisaged; the Chemical Plant Equipment is comprised largely of the Tritium Extraction Facility, some front-end processing, and processing of Target/Blanket spallation and activation products for waste disposal. 


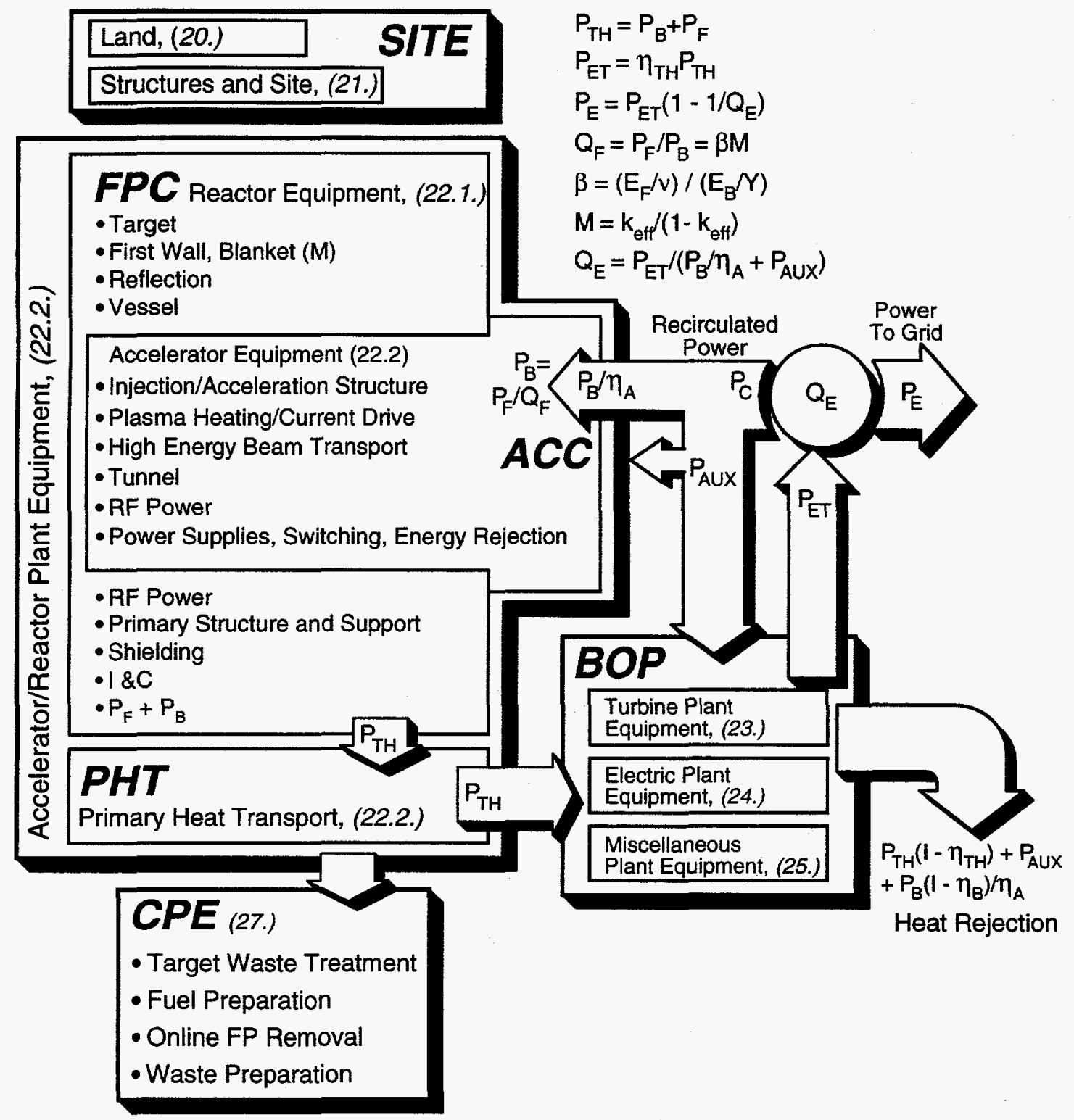

Figure 2. Re-expression of the subsystems and power flows depicted in Fig. 1 in terms of the EEDB ${ }^{11}$ Program of Cost Accounts; as noted in Fig. 1: the APT application envisions neither fission-power generation nor thermal-power conversion; the Chemical Plant Equipment is comprised mainly of the Tritium Extraction Facility and Target/Blanket waste packaging and disposal; and instead of locating the Accelerator in the Reactor Plant Equipment Account 22., for APT the Accelerator Equipment is listed as a separate Account 27., with the Chemical Plant Equipment being reassigned to an Account $4 .^{5}$ 
NORMALIZED CASH-FLOW PROFILE

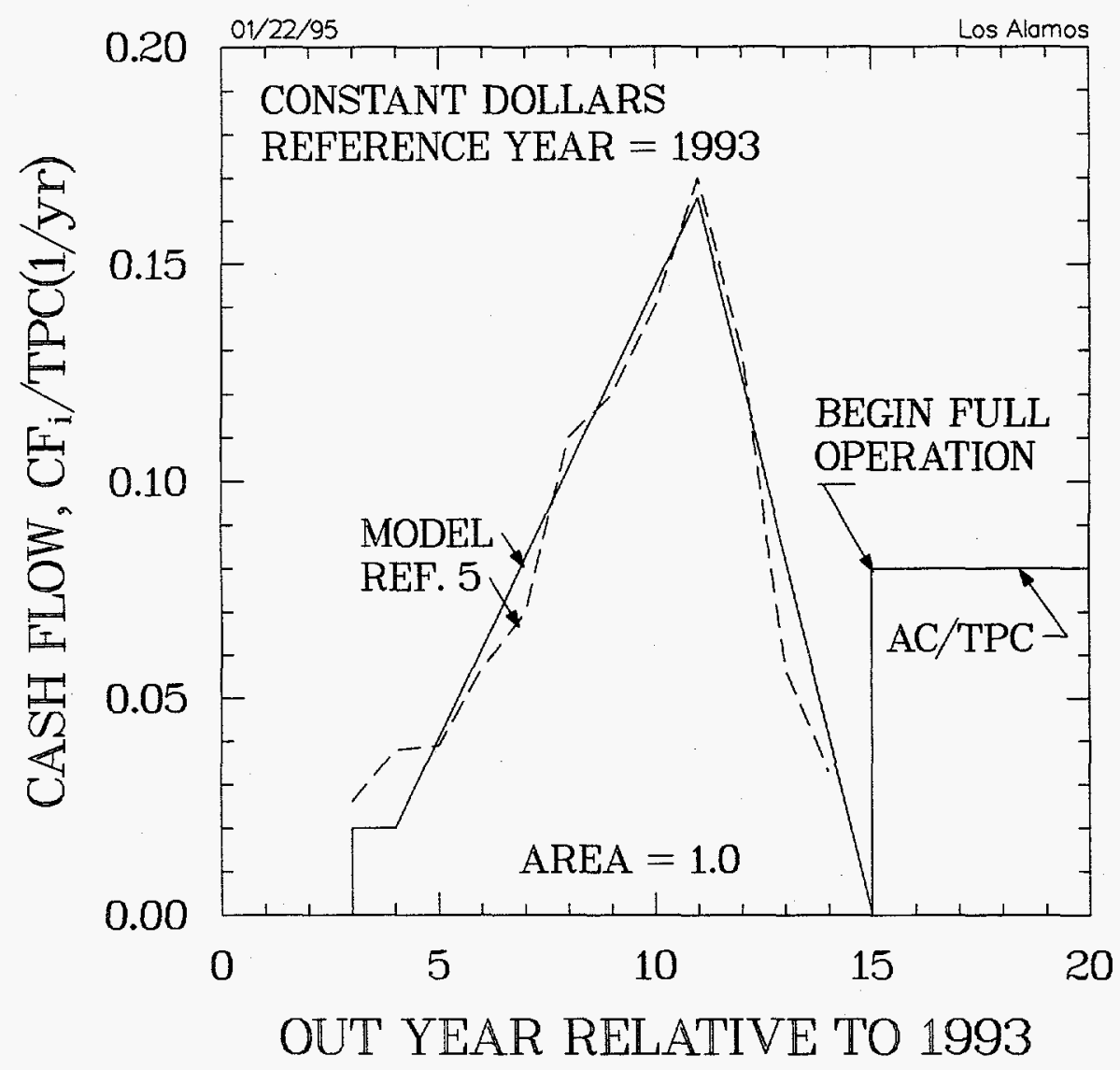

Figure 3. Cash-flow profile used to compute Total Life-Cycle Costs in both the costbased parametric systems model and in the costing of the Ref.-5 preconceptual point design. As assumed in the Ref.-5 detailed preconceptual cost assessment, the CY1993 is the reference year, spending starts in CY1996, and full operation commences in CY2008 after complete expenditure of the TPC, at which time the Annual Charges, $\mathrm{AC}(\mathrm{M} \$ \mathrm{yr})$, associated with Operations and Maintenance (O\&M, Staff, O\&M Consumables, Process Consumables, Utilities, and Other Annual Charges) begins. 


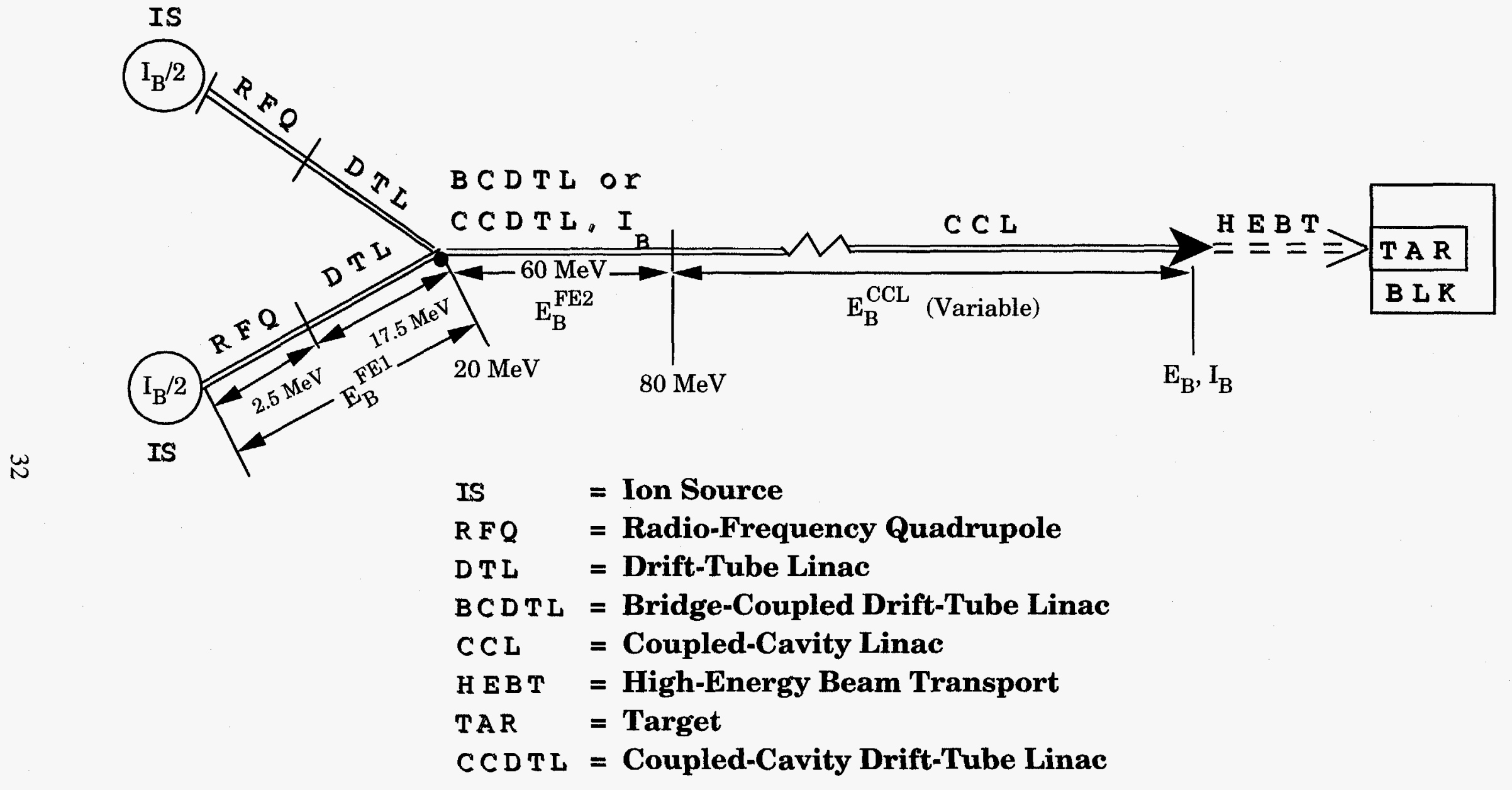

Figure 4. Diagram of parametric accelerator model 8 ; for purposes of the present APT (initial) parametric analysis, the component resolution indicated for costing purposes is not used. 


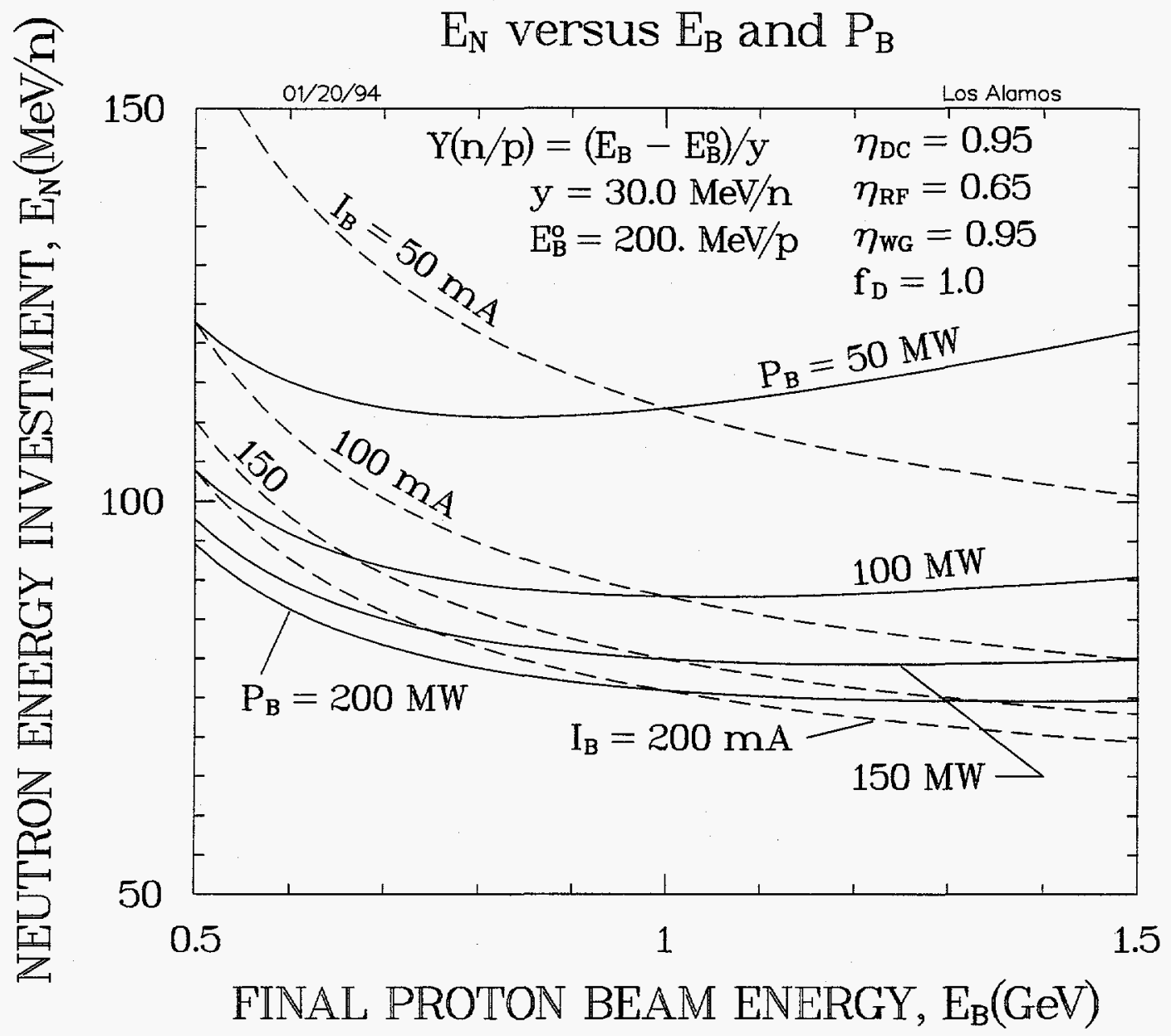

Figure 5. Parametric dependence of "wall-plug " energy investiture to create an accelerator-produced neutron [Eqn. (10)] on beam energy for either fixed beam power [YLD(mol/yr) $\sim \mathrm{P}_{\mathrm{B}}$, Eqn. (3)] or fixed beam current for the fixed parameters indicated. 


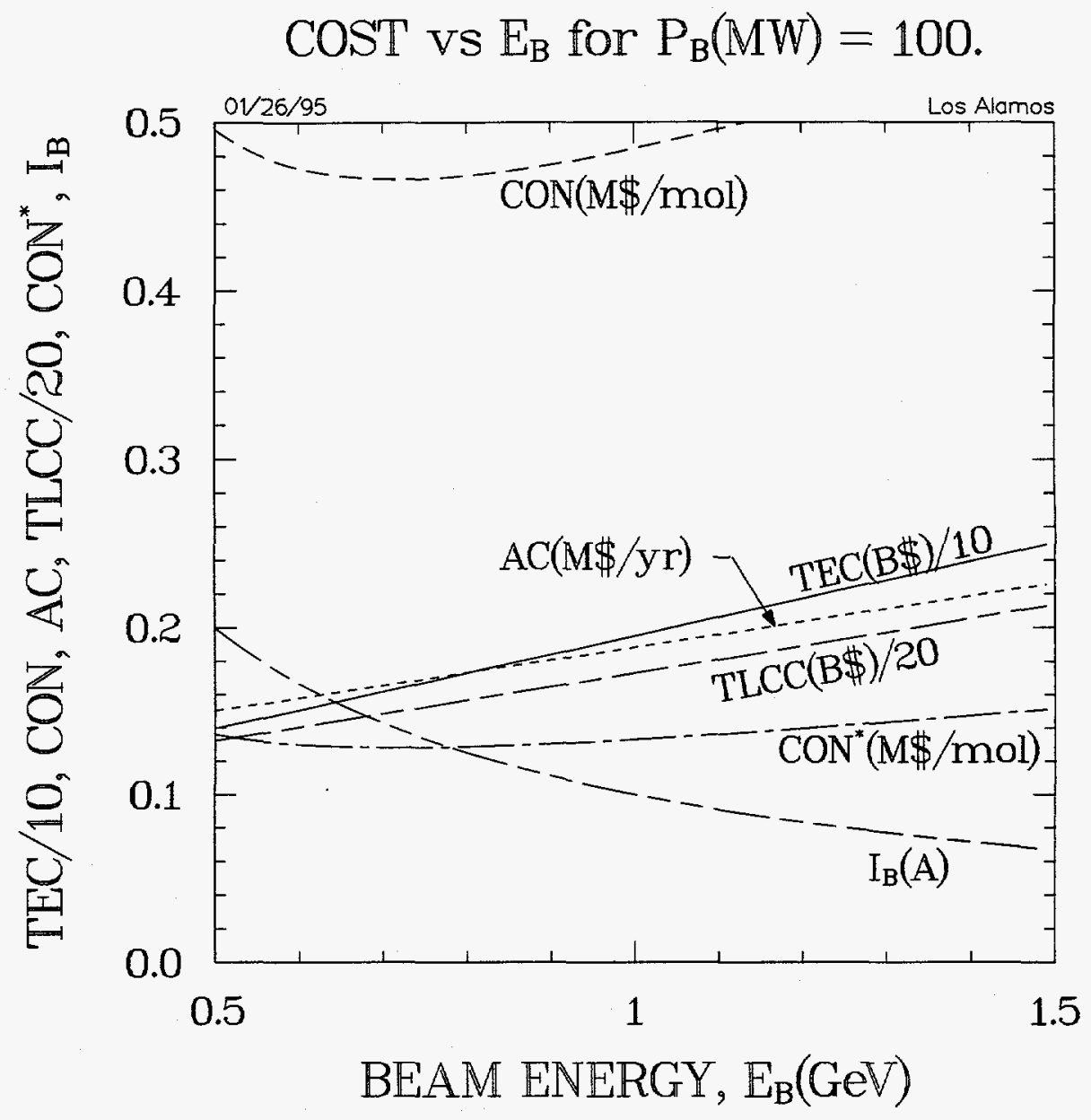

Figure 6a. Parametric dependence of key costs and plasma current on accelerator beam energy for beam powers equal to $P_{B}=100 \mathrm{MW}$, for the basecase parameters listed in Table III. 


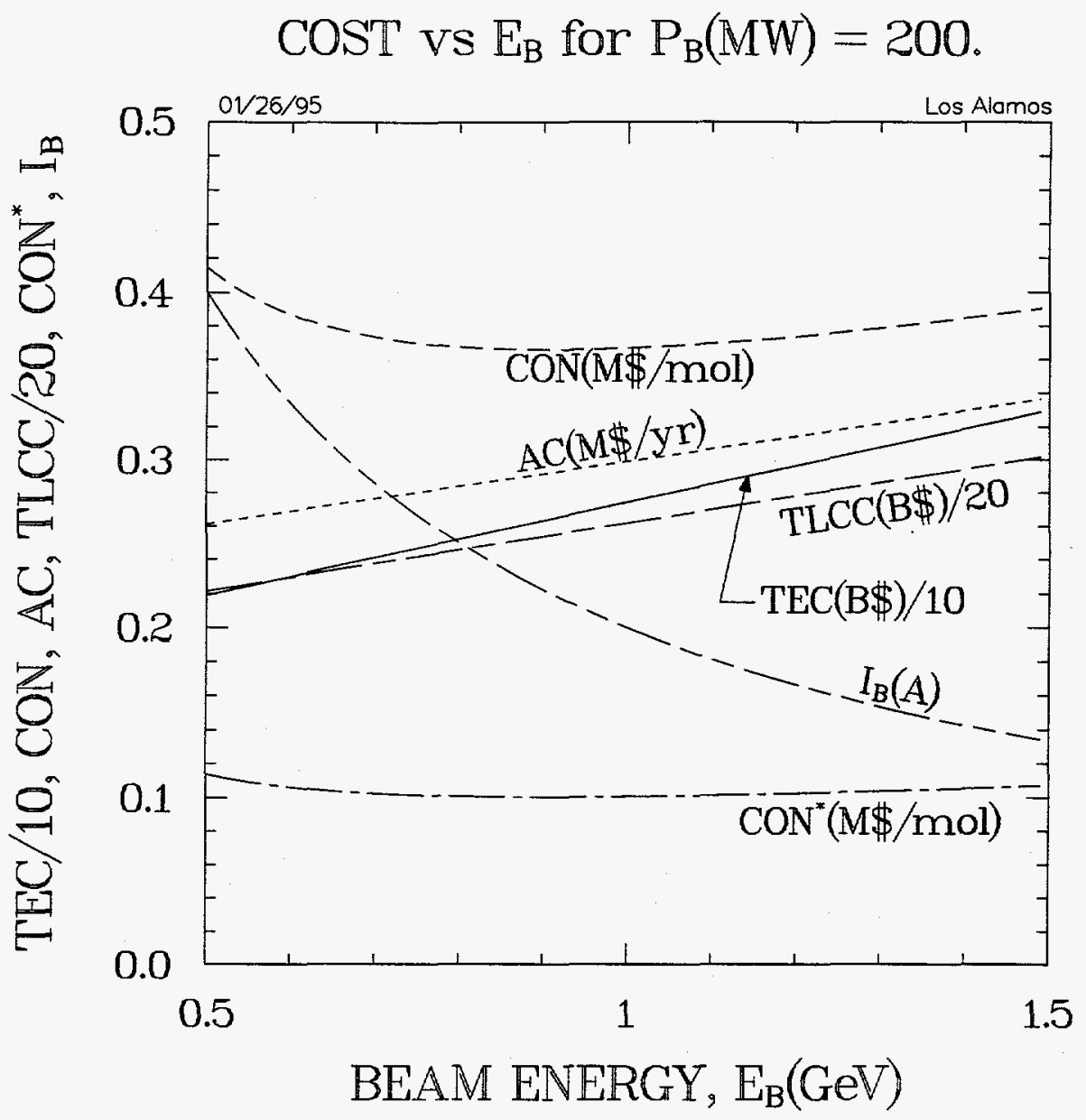

Figure 6b. Parametric dependence of key costs and plasma current on accelerator beam energy for beam powers equal to $P_{B}=200 \mathrm{MW}$, for the basecase parameters listed in Table III. 
CON vs $\mathbb{E}_{\mathrm{B}}$ and $\mathrm{P}_{\mathrm{B}}$

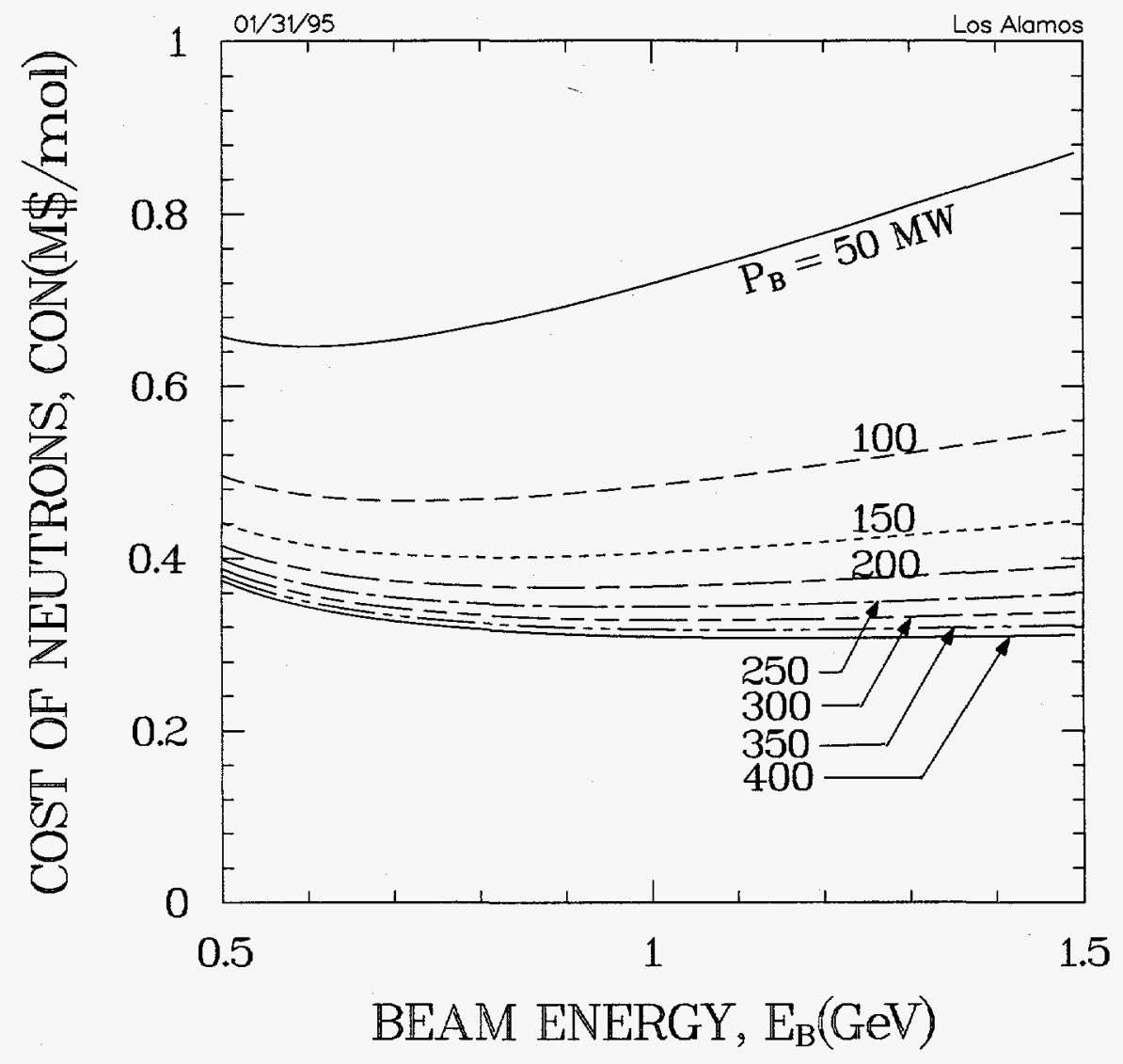

Figure 7a. Beam energy and power dependencies of Cost of Neutrons, CON(M $\$ / \mathrm{mol})$, for the basecase parameters listed in Table III. 
TLCC vs $E_{B}$ and $P_{B}$

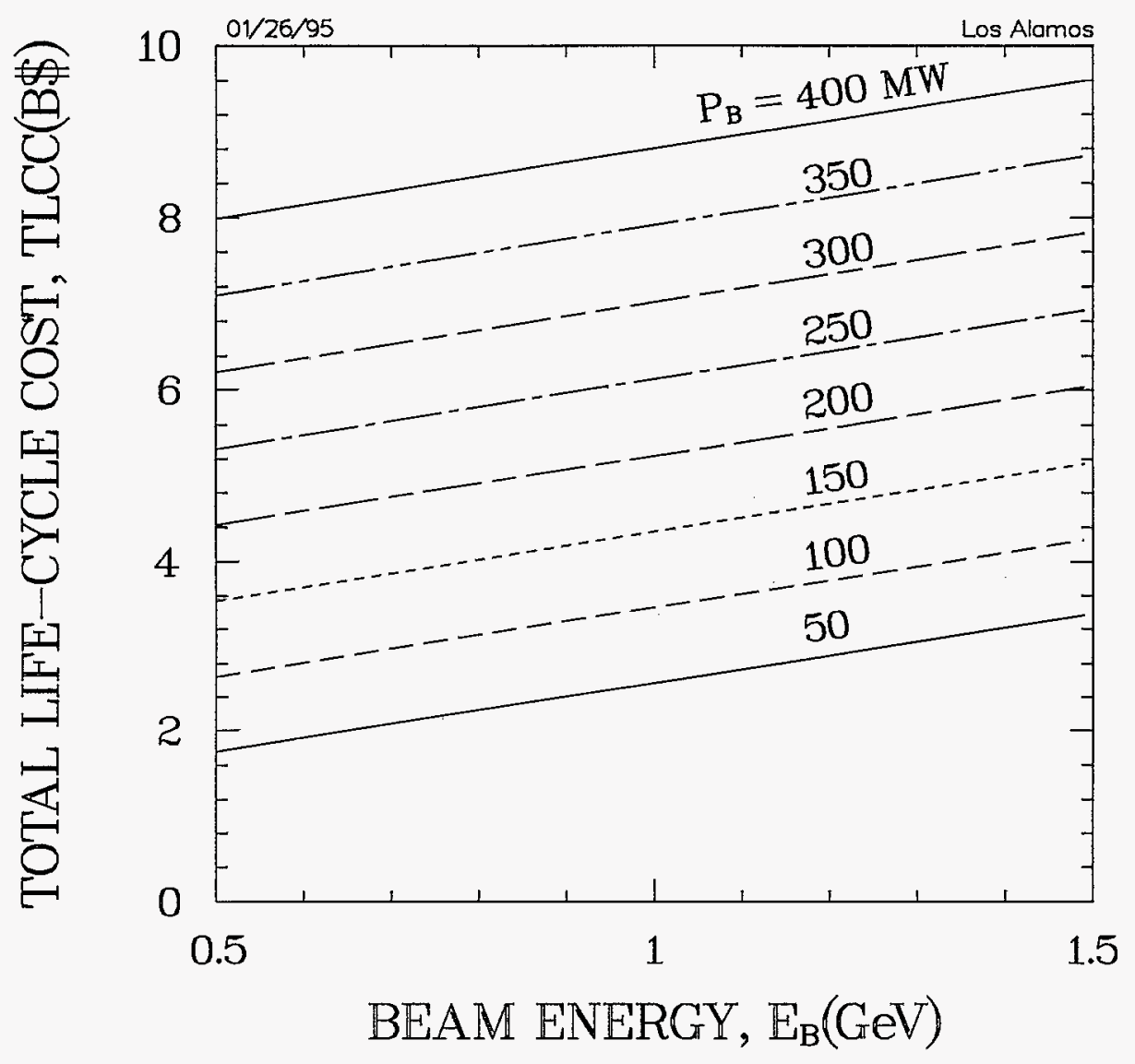

Figure 7b. Beam energy and power dependencies of Total Life-Cycle Cost, TLCC(M\$), for the basecase parameters listed in Table III. 


\section{CON vs $E_{B}$ and YLD}

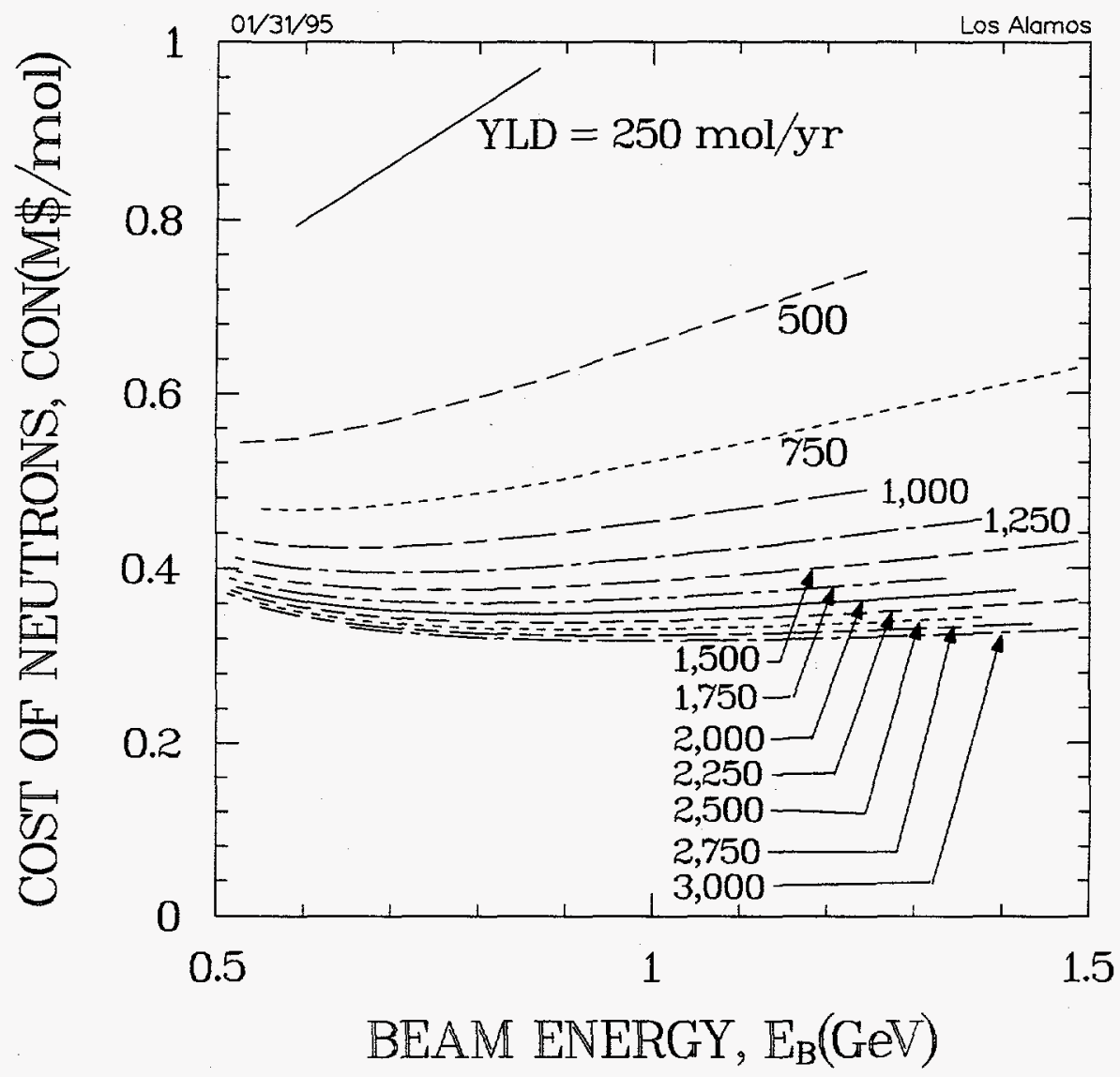

Figure 8a. Beam energy and neutron-production dependencies of Cost of Neutrons, $\mathrm{CON}(\mathrm{M} \$ / \mathrm{mol})$, for the basecase parameters listed in Table III. 


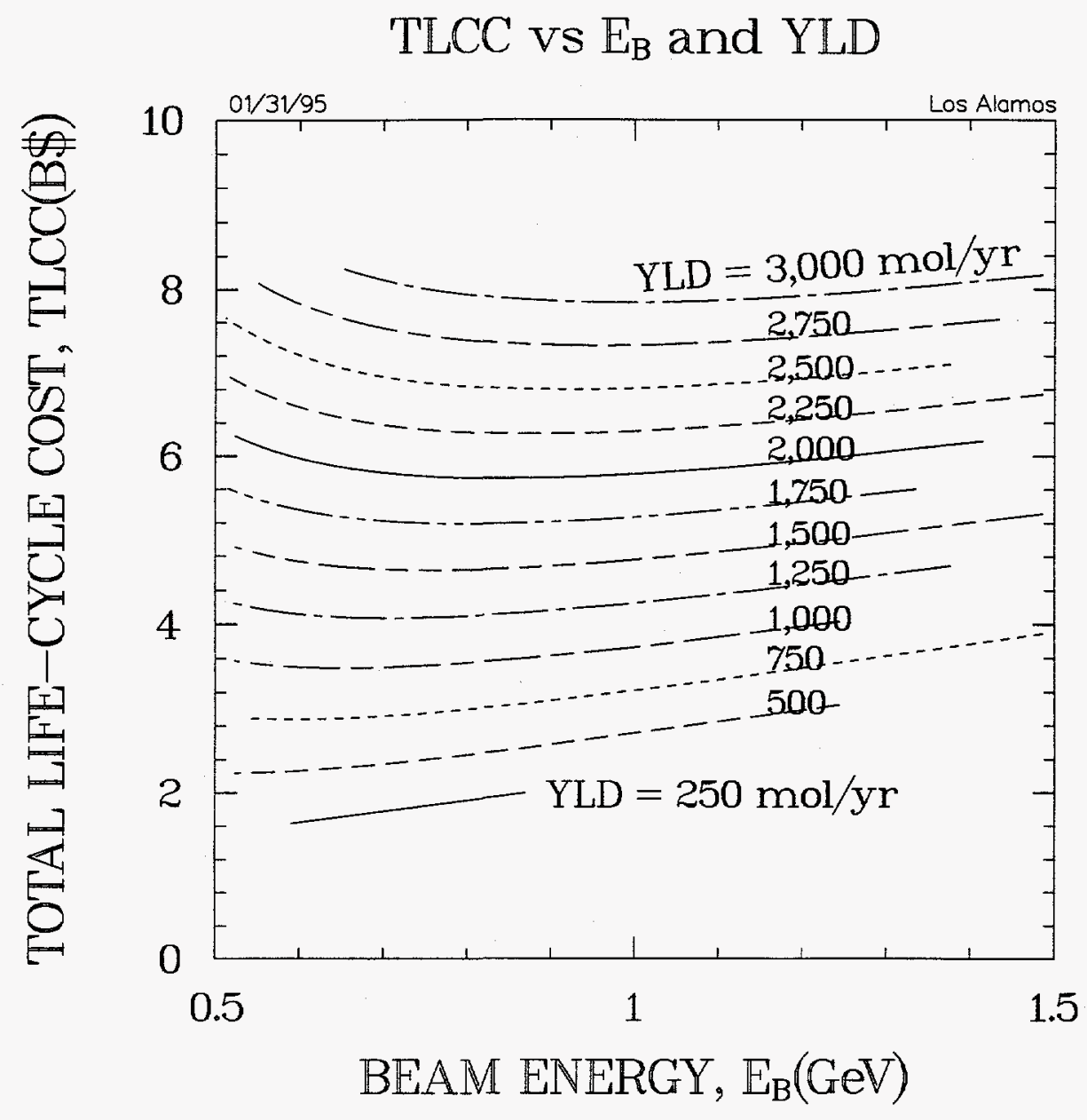

Figure 8b. Beam energy and neutron-production dependencies of Total Life-Cycle Cost, TLCC(M\$), for the basecase parameters listed in Table III. 


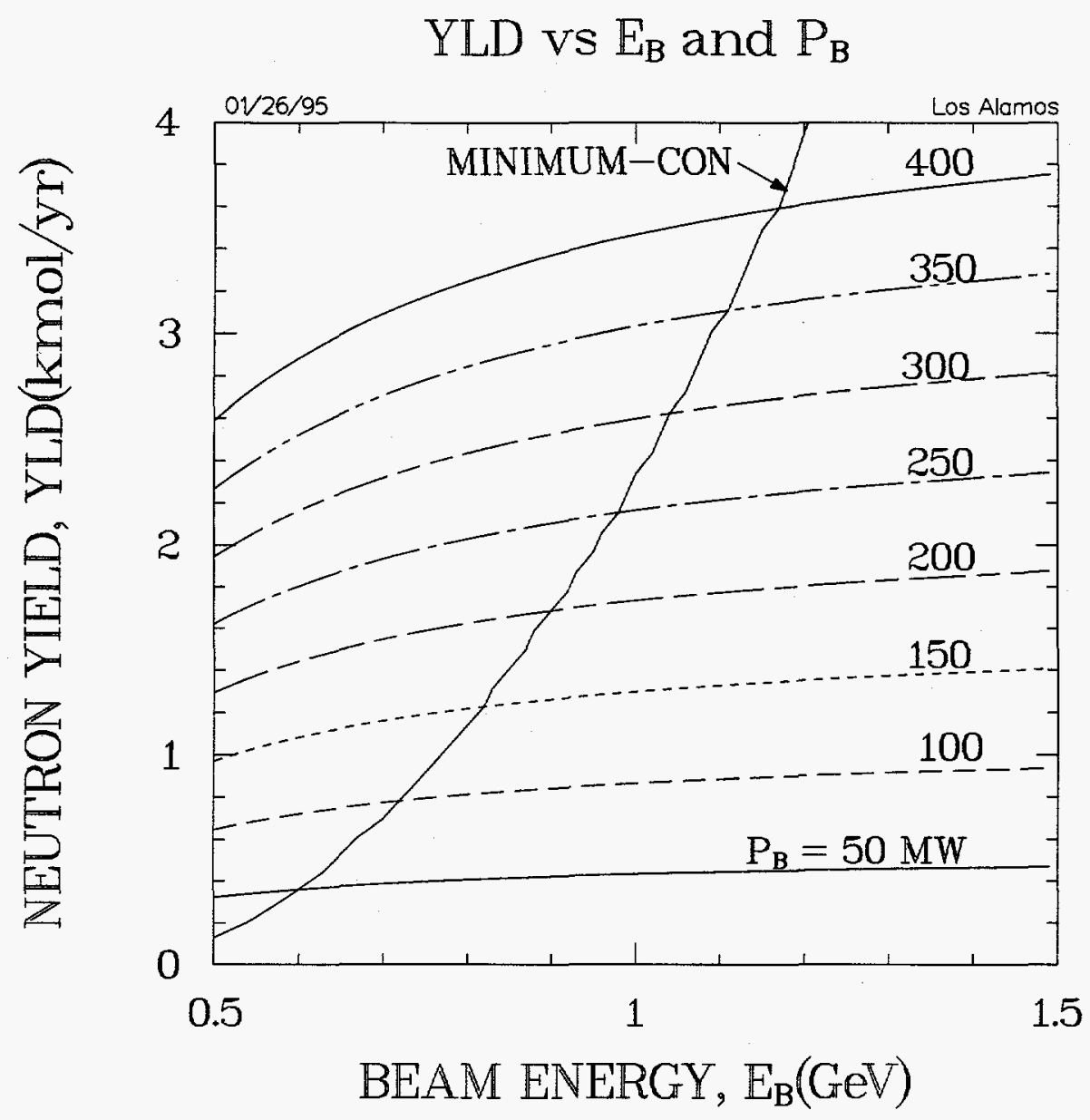

Figure 9. Dependence of facility (rated) neutron-production capacity, YLD(mol/yr), on accelerator-beam energy and power for the basecase parameters listed in Table III; shown also is the locus of minimum $\mathrm{CON}(\mathrm{M} \$ / \mathrm{mol})$ design points; these cost-minimized designs serve as a basis for subsequent parametric (re: Fig. 7a). 


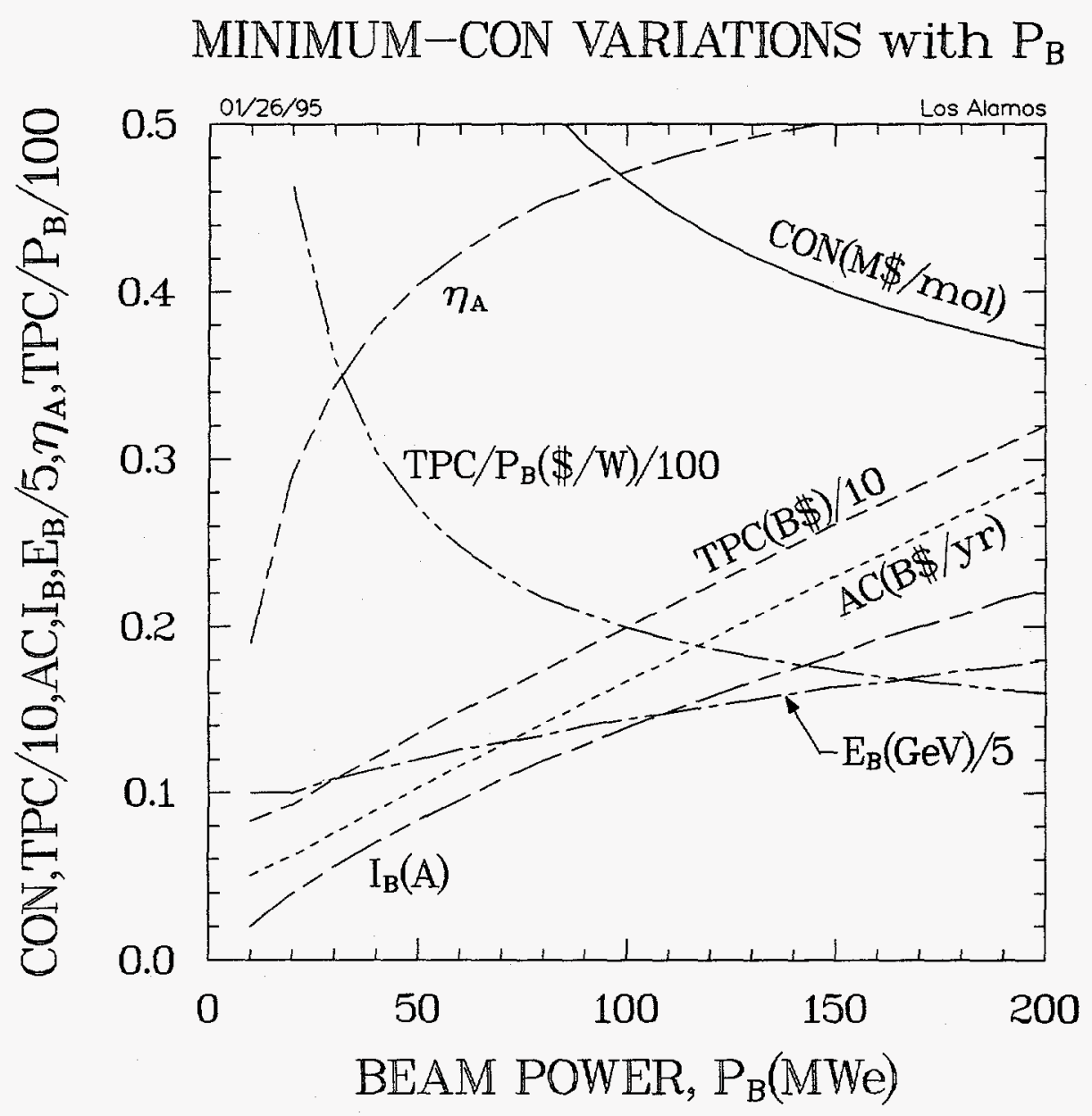

Figure 10. Variation of key costs and machine parameters along the locus minimum-CON values given in Fig. 9. 


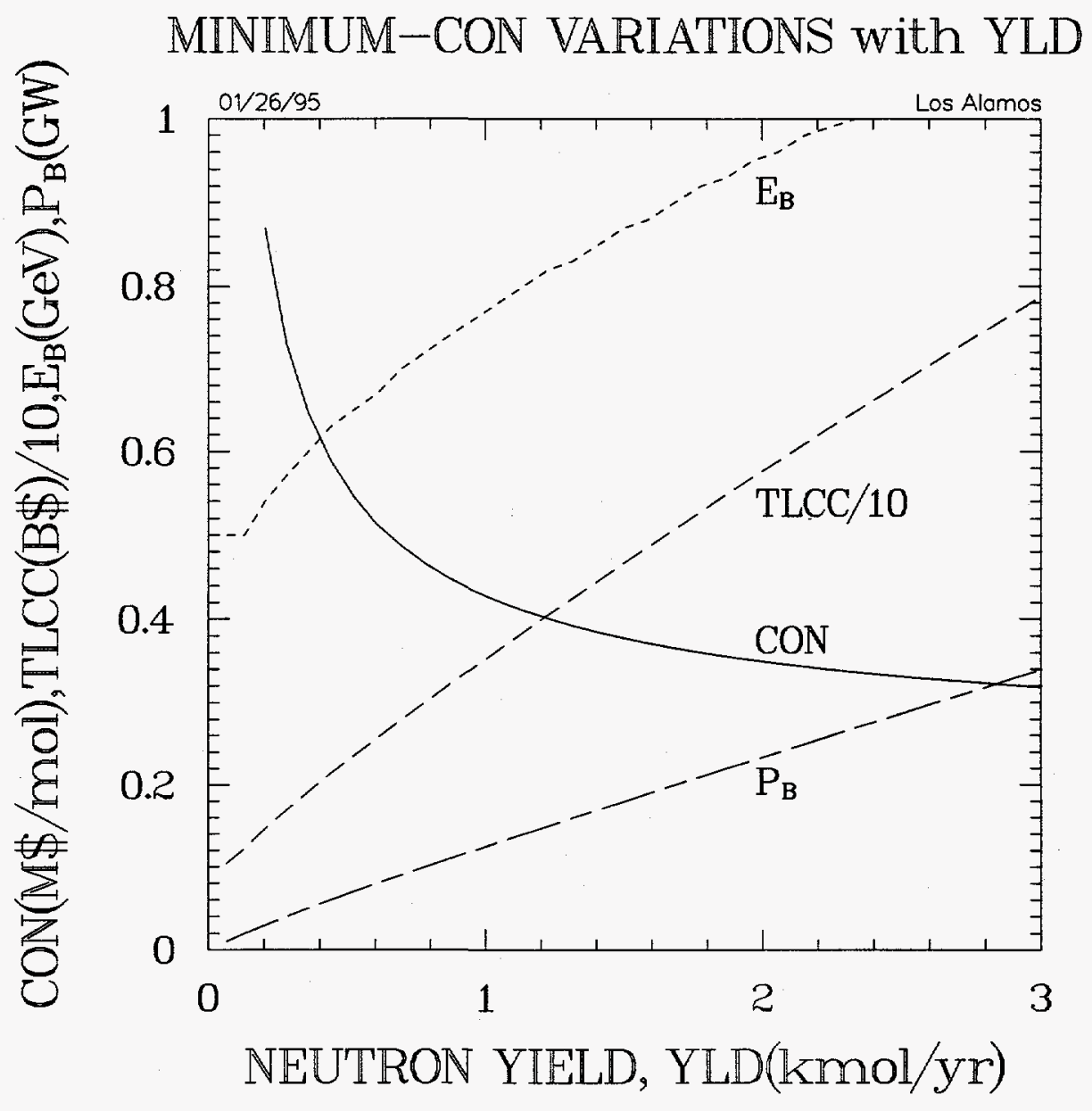

Figure 11. Dependence of unit cost of neutrons, CON(M $\$ / \mathrm{mol})$, and Total Life-Cycle Cost, TLCC $(\mathrm{M} \$)$, on machine neutron-production capacity, YLD(mole/yr), for parameters constrained to the value of minimum CON indicated on Fig 9.; the accelerator beam power and energy corresponding to these conditions are also shown. All other parameters are fixed to those given in Tables I-III. 


\section{MINIMUM-CON COST SPREAD vs $P_{B}$}

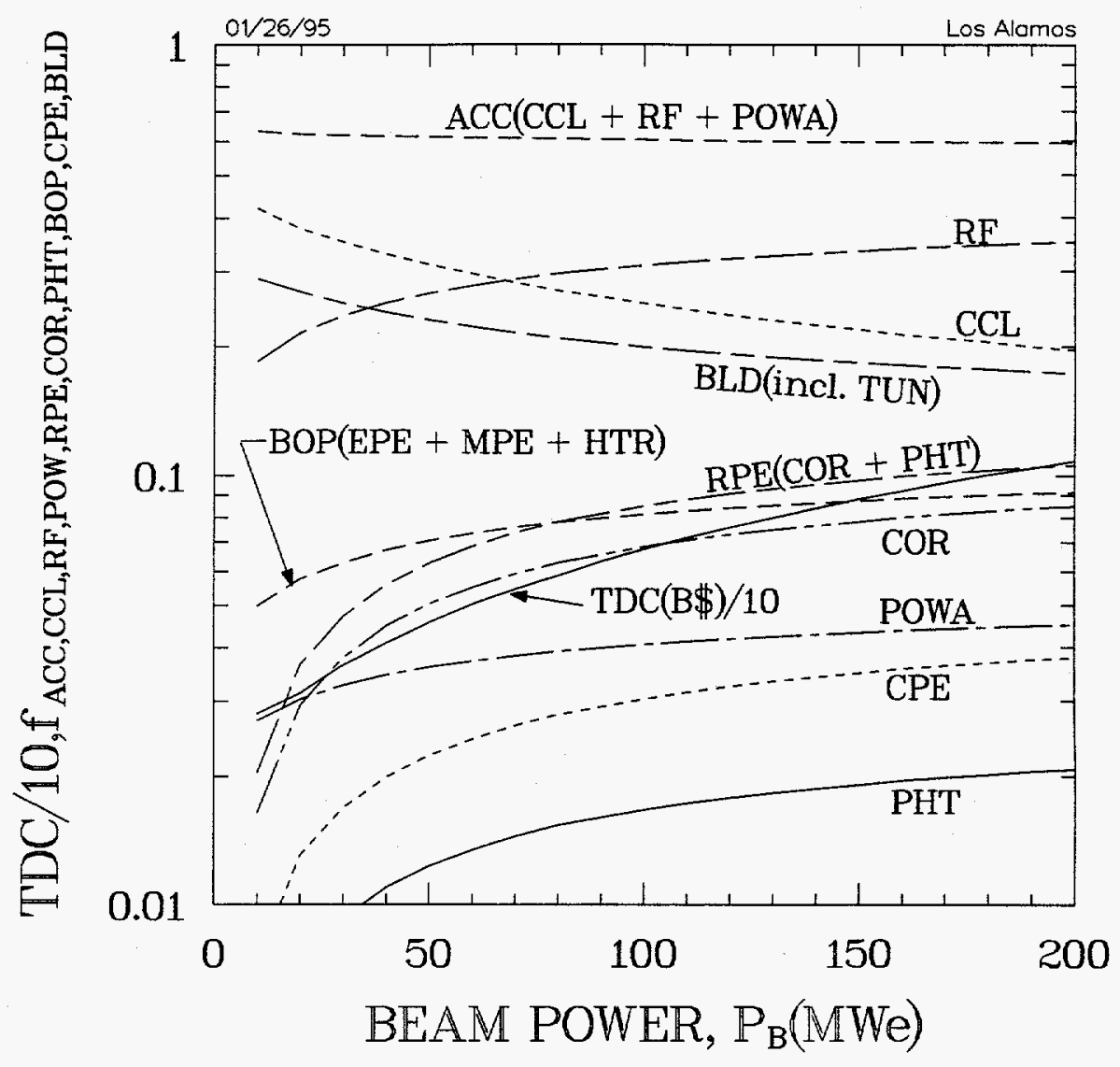

Figure 12. Sample subaccount breakdown of direct costs for the minimum-CON conditions as a function of beam power. The correspondence between these subsystem direct costs and the EEDB Program of Cost Accounts ${ }^{11}$, although tenuous, can be mapped as follows into Table I:

- Account 21. (Structures and Improvements) $\rightarrow$ BLD

- Target/Blanket (COR) Building

- BOP Buildings

- ACC Buildings and Tunnel (TUN)

- CPE Building

- Account 22. (Reactor Plant Equipment) $\rightarrow$ RPE

- Target/Blanket (COR)

- Primary Heat Transport (PHT)

- Account 23. (Turbine Plant Equipment) $\rightarrow$ NA

- Account 24. (Electric Plant Equipment) $\rightarrow$ EPE

- Account 25. (Miscellaneous Plant Equipment) $\rightarrow$ MPE

- Account 26. (Main Condenser Heat Rejection) $\rightarrow$ HTR

- Account 27. (Accelerator Equipment) $\rightarrow$ ACC

- RF Power (RF)

- Accelerating Structure (CCL)

- Accelerator Electrical and Thermal Power (POWA)

- Account 4. (Chemical Plant Equipment) $\rightarrow \mathrm{CPE}$ 


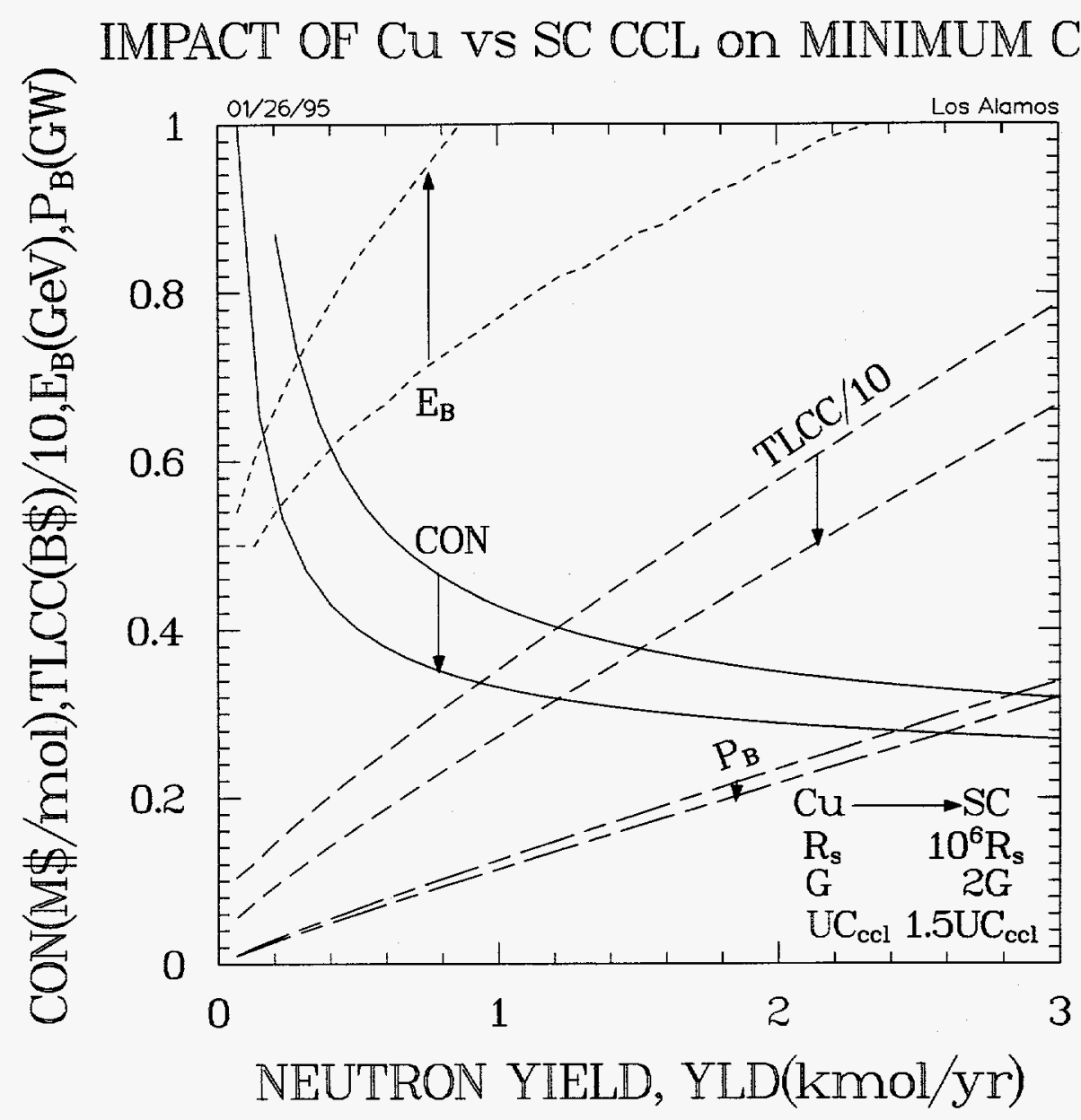

Figure 13. Comparison of resistive $(\mathrm{Cu})$ and superconducting (SC) $\mathrm{CCL}$ options on the basis of cost for the assumptions indicated. 


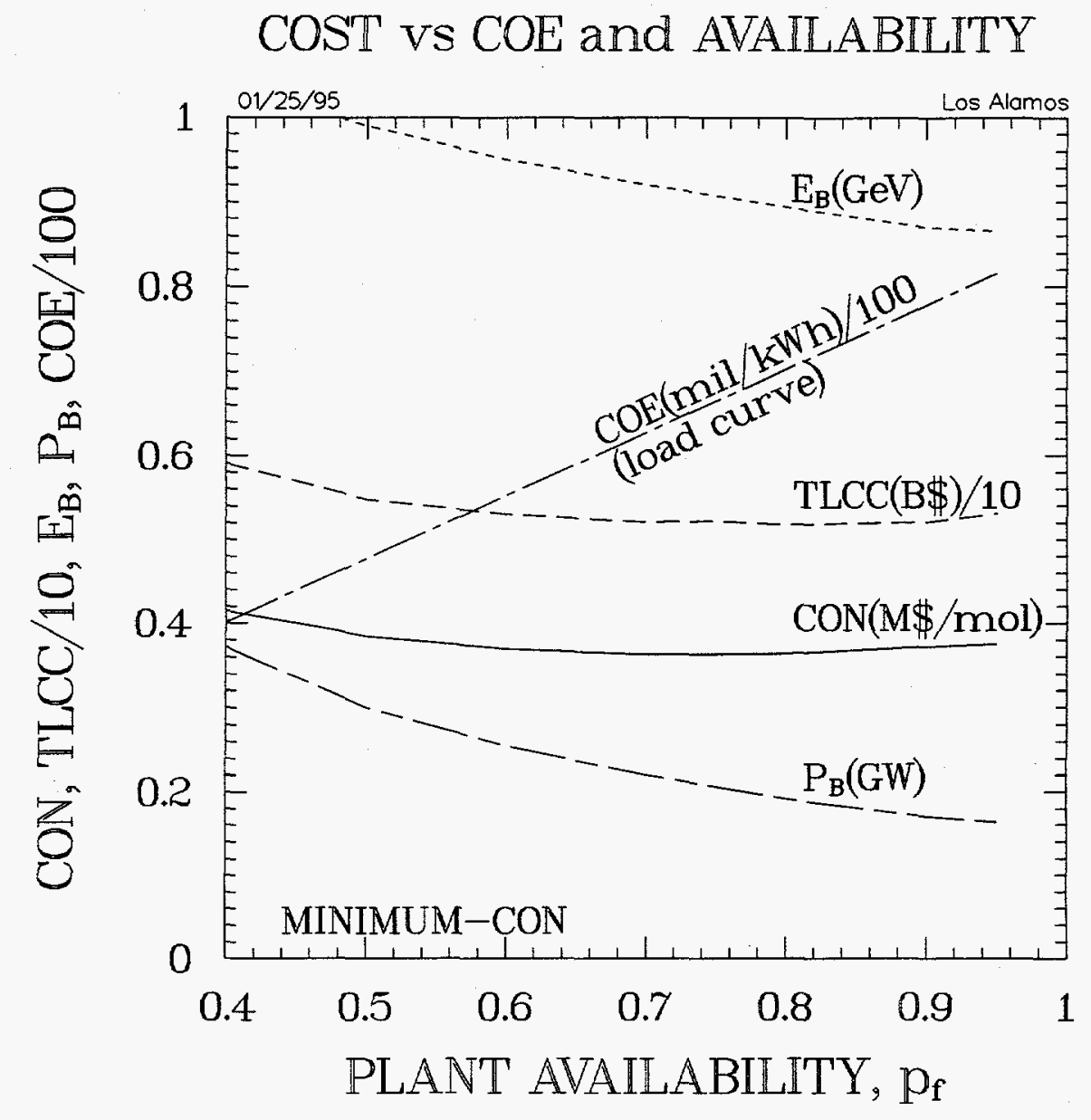

Figure 14. Illustration of trade off between plant availability and cost-of-electricity charges for the fixed annual neutron production and $\mathrm{COE}$ versus $\mathrm{p}_{\mathrm{f}}$ load curve indicated. 